Investigating the Relationship Between Approval and Experiences of Intimate Partner Aggression in Heterosexual Relationships

By

\title{
Saara Cavanagh
}

\begin{abstract}
A thesis
Submitted to the Victoria University of Wellington

In fulfilment of the requirements for the degree of

Master of Science in Forensic Psychology
\end{abstract}

Victoria University of Wellington 


\section{Acknowledgments}

Thank you to my supervisor Dr Louise Dixon for your invaluable help and guidance during this journey. Your belief in my ability, as well as the abilities of the other students in our lab, is what makes you a great supervisor. It has been a pleasure to work with you on this project and I truly appreciate all the work you put into helping me during the last two years.

Thank you to Dr Laina Isler for your statistical advice. You taught me a lot and always welcomed my questions with a smile.

I would also like to thank the students and staff from the Forensic Psychology Lab for their continuous support and encouragement. I feel very lucky to have completed this project alongside such a brilliant group of people. A special thank you to Sha and Ryan who always had time to discussed gendered theory, send me references, or go for a walk when I needed it, this experience would not have been the same without you two there! Another big thank you to my clinical psychology class who gave me the support and motivation to push through the busy year that was 2017 .

A huge thank you too my parents, Peter and Margaret Cavanagh, for their love and encouragement. I am only here today because of your support. Also, thank you to my Wellington flat family who were always there when I needed them and ensured I took time to enjoy myself.

Finally, thank you to everyone who took the time to help proof read this thesis when my eyes no long saw the typos - Charles, Victoria, Catherine and Emily. Without you this project would have many more errors than would be acceptable. 


\begin{abstract}
This study explored the relationship between participants' approval of intimate partner aggression (IPA) and their experiences of IPA in heterosexual relationships. Male $(n=216)$ and female $(n=299)$ university students completed an online questionnaire that consisted of the Conflict Tactic Scale-2, the Controlling Behaviours Survey-revised, and the Beliefs about Relationship Aggression Scale. Bivariate analyses showed the majority of aggressive and controlling behaviours were perpetrated and experienced at similar rates between men and women. ANOVA found an interaction effect where both male and female participants held greater approval of female-to-male aggression, compared to male-to-female aggression, when provoked by physical, sexual, or psychological aggression, or infidelity. An interaction between participants' gender and the aggressors' gender in the vignettes showed men were significantly more approving of female aggression than women. ANOVA also demonstrated a main effect of perpetration status (aggressive/non-aggressive), where aggressive students approved of IPA more than non-aggressive students, regardless of the participant's or the aggressor's gender. These findings show that participants, especially male participants, hold chivalrous beliefs about IPA in heterosexual relationships. Although this chivalrous pattern also held for aggressive participants, aggressive men and women both displayed significantly higher approval of aggression by both male and female perpetrators than non-aggressive controls. Therefore, this study found perpetrators of IPA not only approve of aggression by their own gender significantly more than non-aggressors, but also tolerate aggression by the opposite gender more readily. The need for treatment to address beliefs that approve of IPA by both partners in heterosexual relationships, rather than gender specific beliefs, is discussed alongside other implications for practice and policy.
\end{abstract}




\section{Table of Contents}

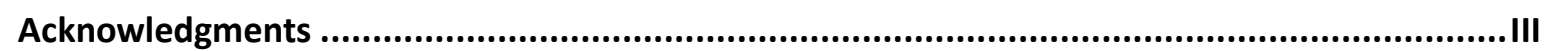

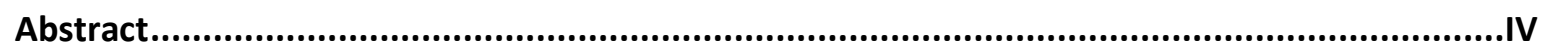

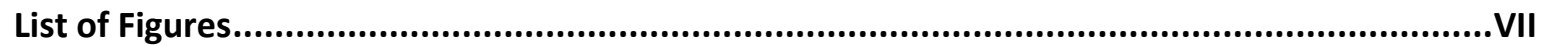

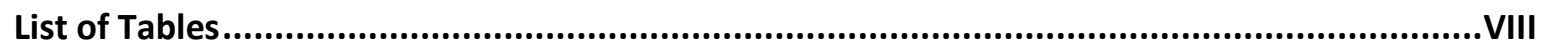

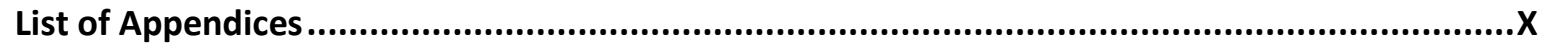

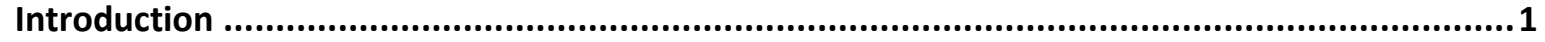

Variations in IPA Theory and Research Methods ..................................................................

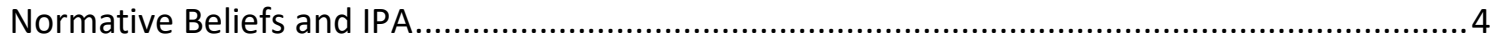

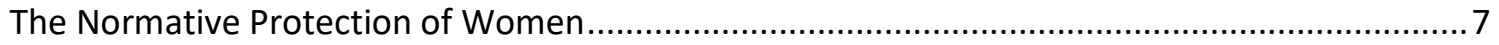

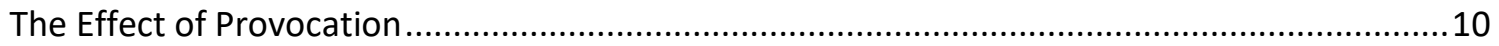

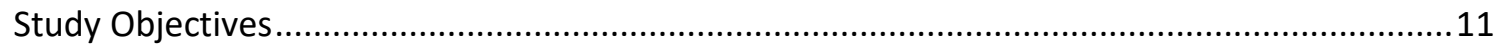

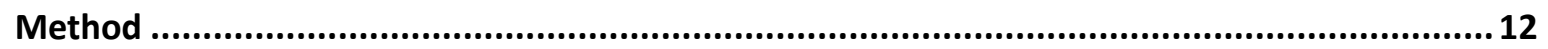

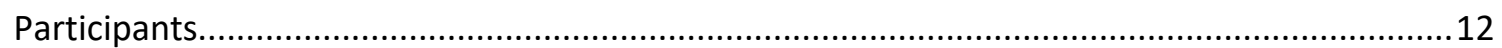

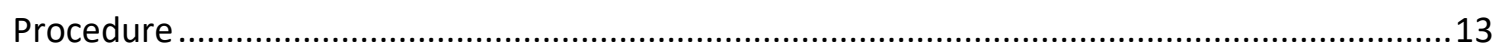

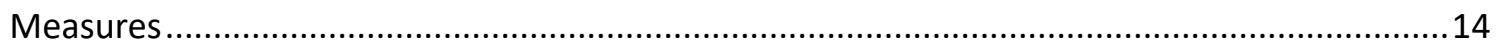

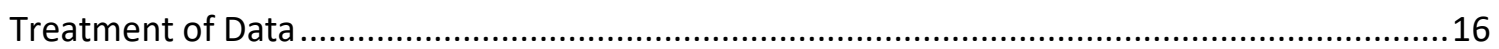

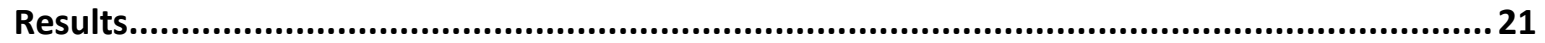

Research Question One: What are the rates and nature of different forms of IPA used by male

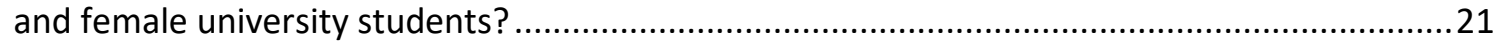

Research Question Two: To what extent do students approve of aggression by third party

heterosexual couples?

Research Question Three: Do students who self-report perpetrating IPA in the previous 12 months differ in their approval ratings of third parties' IPA compared to students who do not self-report perpetrating IPA? 


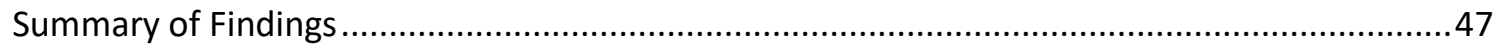

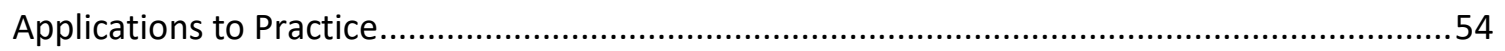

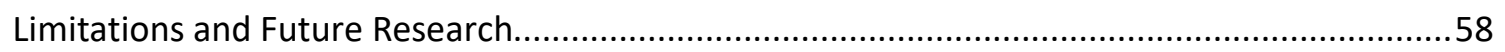

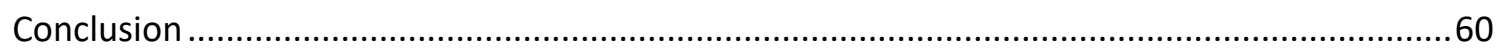

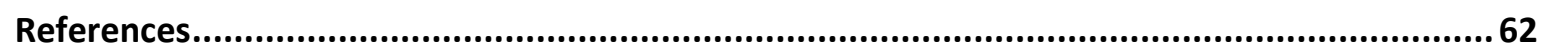

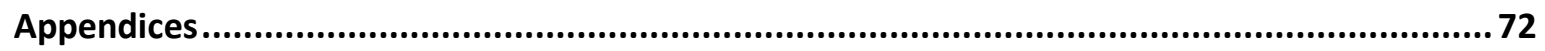

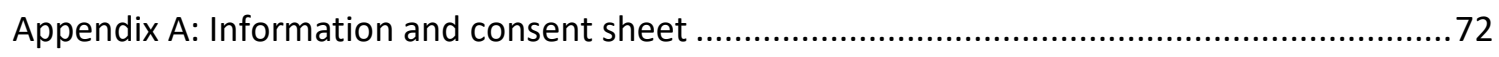

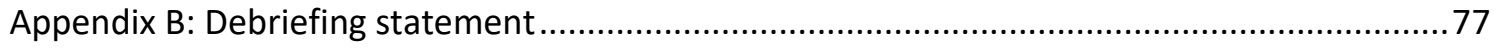




\section{List of Figures}

Figure 1. The mean approval of any aggression used in the BaRAS vignettes, by males and females, in response to various types of provocation $(N=515)$..

Figure 2. Male and female participants' mean approval of any IPA depicted in the BaRAS vignettes $(N=515)$

Figure 3. The mean approval of physical aggression (a slap or punch) used by either and man or a woman in response to various types of provocation in the BaRAS vignette $(\mathrm{N}=515)$

Figure 4. Pictorial representation of female participants' approval of IPA used by either a male or female in a heterosexual relationship; in the context of different types of provocation $(n=299)$

Figure 5. Pictorial representation of male participants' approval of IPA used by either a male or female in a heterosexual relationship; in the context of different types of provocation $(n=216)$

Figure 6. Pictorial representation of male and female participants' approval of IPA used by either a male or female aggressor $(N=515)$.

Figure 7. Aggressive $(n=186)$ and non-aggressive $(n=329)$ men's and women's mean approval of IPA used by a male or female aggressor depicted in the BaRAS vignettes $(N$ $=515)$ 


\section{List of Tables}

Table 1 The frequency of tactics used and experienced by men and women during times of conflict with their intimate partner in the 12 months prior to completing the questionnaire $(N=515)$

Table 2 Differences between tactics used and experienced by men and by women separately during times of conflict with their intimate partner in the 12 months prior to completing the questionnaire $(N=515)$

Table 3 The difference between men's and women's use and experience of various tactics during times of conflict with their intimate partner in the 12 months prior to completing the questionnaire $(N=515)$

Table 4 Pairwise comparisons; mean differences in approval of physical aggression, used by men and women, in response to various types of provocation $(N=515)$

Table 5 Male $(n=216)$ and female $(n=299)$ participants' mean approval of physical aggression used in response to various types of provocation, as presented in the BARAS vignettes

Table 6 Pairwise comparisons; male participants' mean differences in the approval of physical aggression used in response to various types of provocation $(n=216)$.

Table 7 Pairwise comparisons; female participants' mean differences in the approval of physical aggression used in response to various types of provocation $(n=299)$.

Table 8 The mean approval of physical aggression used by either a man or a woman in response to various types of provocation, as presented in the BARAS vignettes

Table 9 Pairwise comparisons; mean differences in the approval of physical aggression used in response to various types of provocation when the aggressor is a female $(N=515) .40$ 
Table 10 Pairwise comparisons; mean differences in the approval of physical aggression used in response to various types of provocation when the aggressor is a male $(N=515)$ 


\section{List of Appendices}

Appendix A: Information and Consent............................................. 72

Appendix B: Debriefing Statement................................................ 77 


\section{Introduction}

Intimate partner aggression (IPA) refers to physical, sexual and/or psychological aggression or violence used between intimate partners of any age, gender, ethnicity, sexuality, or relationship status (Dixon \& Graham-Kevan, 2011). Controlling behaviours, such as economic deprivation, possessive behaviours, insults, threats, and intimidation, have also been shown to form part of IPA (Graham-Kevan \& Archer, 2009), and are included in New Zealand's legal definition of domestic violence (Domestic Violence Act, 1995). IPA has been recognised by the World Health Organisation (WHO) as a pervasive global health issue (Mandela \& Brundtland, 2002). Although differences in methodological rigor make it hard to gain accurate prevalence rates, large-scale representative studies suggest that approximately 20 to 30 per cent of those living in Western countries experience IPA in their lifetime (Desmarais, Reeves, Nicholls, Telford, \& Fiebert, 2012). In New Zealand, the magnitude of IPA is shown by crime survey statistics, finding that 13.8 percent of men and 26.1 percent of women report experiencing physical, psychological, and sexual victimisation from a partner in their lifetime (Ministry of Justice, 2015). In the year 2013, 4.4 percent of men and 5.7 percent of women in New Zealand reported experiencing sexual or physical partner violence (Ministry of Justice, 2015).

IPA results in direct and immediate injuries to victims, and also indirectly increases the risk of developing chronic physical and mental health issues (Campbell, 2002; ExnerCortens, Eckenrode, \& Rothman, 2013). For example, using data from the National Violence Against Women Survey, Coker et al. (2002) found that, for men and women, experiencing IPA was associated with an increased risk of developing depressive symptoms, substance use, chronic disease, and chronic mental illness. In addition to the costs to individuals, IPA and child abuse have been estimated to cost the New Zealand Government $\$ 4.1$ billion - 
$\$ 7$ billion annually (Kahui \& Snively, 2014). Together, these findings demonstrate that IPA is a prominent concern domestically and internationally and needs a social response.

Although IPA transcends age boundaries, it is important to note that rates of IPA perpetration and victimisation are typically highest during emerging adulthood; ages 16 to 24 years old (Archer, 2000; Archer \& Graham-Kevan, 2003). The New Zealand Crime and Safety Survey (NZCC; Ministry of Justice, 2015) shows the extent of this problem, with 13.8 percent of those aged 15-19 reporting IPA victimisation in 2013, compared to 5.1 percent of the general New Zealand population. Research with community and university samples has suggested prevalence of IPA among young adults is even higher than reported in surveys using crime victimisation methodology. For example, Magdol, Moffitt, Caspi, and Silva (1998), in a longitudinal study, surveyed and interviewed 777 males and females at age 21 and found that 27 percent had experienced physical IPA in the last 12 months. Similarly, 26 percent of students (mean age 21 years) attending University of Canterbury, New Zealand, reported experiencing physical assault from their partner in the 12 months preceding a study carried out by Straus (2004). These results emphasise the importance of understanding and responding appropriately to IPA in this age group in particular. As such, this study focuses on a sample of university students who were primarily in dating relationships or who are currently single but have been in an intimate relationship in the last 12 months.

\section{Variations in IPA Theory and Research Methods}

The theoretical perspective adopted in IPA research tends to influence the methodological approach and subsequent research outcomes (Esquivel-Santoveña \& Dixon, 2012). Two theoretical perspectives compete to explain the aetiology of IPA. The gendered perspective has been extremely influential and asserts that male violence towards women is directly caused by wider social systems and patriarchal beliefs that reinforce and condone 
male dominance and female subordination (Abrar, Lovenduski, \& Margetts, 2000; Yllo, 1983). From this perspective females are understood as the overwhelming victims of IPA at the hands of their male partners (Dobash \& Dobash, 2001; Yllo, 1983). Although some research has found women are more likely to experience IPA (e.g., Alhabib, Nur, \& Jones, 2010; Tjaden \& Thoennes, 2000), it is important to pay attention to the methodological approaches taken to determine rates of victimisation (Desmarais et al., 2012; EsquivelSantoveña \& Dixon, 2012). Research using samples from women's shelters or accident and emergency departments often estimate high levels of male perpetrated partner violence. Examination of this population provides valuable insight into a clinical sample, however, such findings are not representative of the general population (Gelles, 1990). Further, surveys that ask women about their victimisation in isolation, lack generalisability and lose the opportunity to gain an understanding of relationship dynamics and men's experiences (Esquivel-Santoveña \& Dixon, 2012). This highlights that a gender inclusive perspective (Hamel \& Nicholls, 2006), which explores the experiences of both men and women, may be a more appropriate approach to frame IPA research.

Broadly, a gender inclusive perspective acknowledges that a range of factors contribute to the aetiology of male and female perpetrated IPA (Hamel \& Nicholls, 2006). For example, Dutton's (2006) Nested Ecological Model seeks to understand individual differences in offenders, as well as wider social structures, and suggests that a range of factors may influence someone to perpetrate IPA. This model describes four areas or systems that interact to manifest in IPA; macro-systems (broad cultural beliefs), exosystems (immediate social structures and peers), microsystems (family unit or relationship patterns) and the ontogenetic level (an individual's developmental history and emotional reactions). Stith, Smith, Penn, Ward, and Tritt (2004) conducted a meta-analysis that supported the use of a multifactorial approach to IPA. Using Dutton's (2006) Nested Ecological Model as a 
framework to explore IPA risk factors, Stith, Smith et al. (2004) produced 308 distinct effect sizes across Dutton's four systems, with traditional sex role ideology exerting a moderate effect at best. Such findings showcase that patriarchal beliefs play a lesser role than is promoted by the Gendered perspective.

Reinforcing the notion that a gender inclusive perspective may be a more appropriate approach to frame IPA research are the results from surveys with nationally representative samples of men and women who report experiencing equal rates of IPA (Straus, Gelles, \& Smith, 1990). For example, the National Family Violence Surveys (NFVS) conducted in 1975 and again in 1985, showed approximately 12 percent of both men and women reported engaging in IPA during those years (Straus et al., 1990). Nationally, representative surveys, such as the NFVS, are beneficial as they likely reflect the experiences of the general population and therefore provide a more robust and accurate indication of the rates and nature of IPA (Esquivel-Santoveña \& Dixon, 2012). These surveys are not without their critics, who state that asking about conflict neglects those women experiencing abuse in the context of control and therefore inflates the proportion of male victims found (e.g., Dobash \& Dobash, 2004). However, research that has explained the role of control in IPA has found men and women experience IPA in the context of control at similar rates (Laroche, 2007). In New Zealand, the NZCSS found that both men and women experience IPA at similar in the last twelve months (4.4 percent of men and 5.7 percent of women; Ministry of Justice, 2015). Such equality between the sexes, in addition to the complexity of factors associated with the aetiology of IPA, does not support the notion that patriarchy is the sole cause of IPA.

\section{Normative Beliefs and IPA}

A person's normative beliefs or 'an individual's cognitions about the acceptability or unacceptability of a behaviour" is often theorised as an important driver of general human 
aggression (Huesmann \& Guerra, 1997, p. 409). Through the process of socialisation, collective norms in a person's immediate or broader environment are internalised as individual normative beliefs (Akers \& Sellers, 2012). For this reason, collective norms and individual normative beliefs are likely related (Kelmendi \& Baumgartner, 2017). Indeed, research has shown that perpetrators and victims of IPA have higher rates of violence socialisation and approval of IPA. However, exposure to IPA in a person's immediate environment may be more powerful than wider collective norms (Huesmann \& Guerra, 1997; Simons, Lin, \& Gordon, 1998). For example, if a child witnesses their father hitting their mother, they are less likely to internalise a wider chivalrous norm to protect women that may be enacted in their community or wider social group (Felson \& Feld, 2009).

Using an information processing model of problem solving and human aggression, Huesmann (1988) proposed that when people encounter a social problem they search their memories for cognitive scripts, otherwise known as rules for what behaviours are enacted, in what order, in a particular situation. He argued that normative beliefs are used to filter out inappropriate scripts for behaviour and, therefore, play an important role in predicating whether aggressive behaviours occur. Huesmann's theory highlights the necessity of an individual's normative beliefs that approve of aggression for an aggressive act to ensue. Indeed, evidence has shown the validity of this theory. Huesmann and Guerra's (1997) study of 1,550 children found that children's normative beliefs about aggression correlated significantly with their use of aggressive behaviour against others, with those children who believed it was normative to act aggressively more likely to do so than those who believed aggression was unacceptable. An individual child's normative beliefs were also highly correlated with their perception of how acceptable they thought other children would think aggressive behaviour was. In the study, children who thought aggressive behaviour was acceptable, also thought most other children believed it to be acceptable as well. These 
findings suggest that an individual's beliefs about aggression, as well as their perception of broader social norms that condone aggression, can influence whether an aggressive response is enacted in a given situation. However, the relationship between individual beliefs and wider collective beliefs or norms are rarely tested in IPA research.

Research investigating the role of individual normative beliefs in IPA has found a strong correlation between an individual's approval of partner violence and IPA perpetration (e.g., Archer \& Graham-Kevan, 2003; Archer \& Haigh, 1999). Meta-analysis shows there is little support for the relationship between traditional sex role ideology and men's aggression towards their female partners (Sugarman \& Frankel, 1996). Although, Stith, Smith et al (2004) found a moderate effect for this risk factor, their inclusion of two of the four studies in their meta-analysis have been heavily criticised on methodological grounds and this result has generally been disregarded in the literature (Dutton, 2006). However, men's positive attitudes about violence against women in relationships has been shown to be a reliable risk factor for male perpetrated IPA in heterosexual relationships (Stewart, Flight, \& Slavin-Stewart, 2013; Stith, Rosen, et al., 2004). Indeed, Stewart et al. (2013) argue that addressing such beliefs should form an important part of treatment programmes in correctional settings.

On the face of it, this finding provides some support for a patriarchal theory of IPA. However, research investigating both men's and women's approval of aggression towards an intimate partner of the opposite sex has shown that this belief is related to perpetration of IPA for both sexes. For example, Dibble and Straus (1980) found that 27.6 percent of men and women from a nationally representative sample thought it was necessary, normal, or good to slap a spouse. Additionally, of those participants, 33 percent reported using violence against a partner, which suggests a relationship between acceptance and use of IPA. Similarly, Archer and Graham-Kevan (2003) investigated the beliefs of male and female students, as well as, male prisoners, and females in shelters. It was found that, for both males and females, beliefs 
that aggression was necessary to teach a partner a lesson, were significantly correlated with causing an injury to one's partner. These beliefs also correlated with males (prisoner and male students, $n=61$ ) hitting their partners and females (shelter women and female students, $n=57$ ) throwing objects at their partners (Archer \& Graham-Kevan, 2003). Taken together, these findings suggest that acceptance of partner aggression in general may offer a better explanation for both male and female perpetrated IPA than male patriarchal beliefs that condone violence against women.

While both the gendered and gender inclusive perspectives suggest that beliefs about the acceptability of IPA to a partner play a role in the perpetration of IPA, the theories do not agree on which sex holds these beliefs and uses aggression as a result. The gendered theory argues that patriarchal beliefs, that promote violence against women, are the cause of mens' violence towards the women they are in relationships with (R. E. Dobash \& Dobash, 2001). From this perspective, long-term change rests with changing patriarchal beliefs that condone men's violence against women. However, a gender inclusive perspective would argue the need to test the role of beliefs approving of IPA in both men and women. Indeed, Huesmann's (1988) Model would not preclude such a test. This study will explore participants' approval of IPA used by third parties in a sample of male and female university students. In addition, differences between those who do and do not act aggressively towards their partners will be explored. This study then aims to determine the relationships between the two concepts.

\section{The Normative Protection of Women}

Ambivalent Sexism Theory (Glick \& Fiske, 1996) argues that prejudice against women is comprised of both hostile and benevolent sexism. Hostile sexism reflects discrimination against women that is negative and overt (that is, the idea that women are 
inferior to men), while benevolent sexism refers to discrimination against women that appears positive (for example, women are delicate and in need of protection from men). Ambivalent Sexism Theory argues benevolent sexism is needed to counter the effects of hostile sexism so that men can gain access to female intimacy, support, and reproduction (Glick \& Fiske, 1996). Some scholars argue that the expectation that men protect women (benevolent sexism) actually discourages men from engaging in violence against women (Allen, Swan, \& Raghavan, 2009; Zimring, Mukherjee, \& Winkle, 1983). In support of this, research has revealed that men are less likely to act aggressively when the target is a female (Davidovic, Bell, Ferguson, Gorski, \& Campbell, 2011; Felson, Ackerman, \& Yeon, 2003). For instance, Cross, Tee, and Campbell (2011) asked 59 men and 115 women to imagine themselves in various vignette scenarios, in which they were provoked by either their partner, same sex friend, or opposite sex friend. Results revealed that men displayed lower aggression in situations where the target was female.

Felson (2000) described this societal protection of women as a chivalrous social norm. In contrast to gendered explanations of IPA, he argues that, in Western societies, hostile patriarchal beliefs and violence against women are not expressed as the social norm but are instead perceived as deviant behaviour. In support of this idea, research has shown that people are more disapproving of aggression by men directed at females than aggression by females directed at males (Felson \& Feld, 2009; Sorenson \& Taylor, 2005). Felson and Feld (2009) presented 810 American adults with a scenario where an offender gets angry and hits a victim. The gender of the offender and victim was manipulated, as was the intimacy of the relationship. It was found that, compared to other gender combinations, respondents were more likely to condemn men who were violent against women and favoured reporting them to the police. In addition to this, research has found that participants, especially males, were much less likely to administer an electric shock to a female than a male (Taylor \& Epstein, 
1967). These findings suggest that in Western society, the norms and beliefs for appropriate male behaviour favour the protection of women (chivalry), rather than violence against women (hostile sexism).

As well as highlighting the disapproval of male to female aggression, the above findings also show that female violence against men is tolerated more than male violence toward women. This point is demonstrated in a study of 624 students, aged 14 and 15 years, where 40 percent of girls and boys condoned a girl hitting her boyfriend, while less than 20 percent agreed it was okay for a boy to hit his girlfriend (Reeves \& Orpinas, 2012). Sorenson and Taylor (2005) also investigated how the gender of an assailant impacted on the respondents' beliefs about the acceptability of IPA and the appropriate consequences for that behaviour. It was found that women's use of IPA was judged less harshly than men's, less "wrong" and less likely to be illegal. Some scholars have argued that this trivialisation of violence by women occurs because individuals use traditional gender stereotypes (for examples men are powerful and threatening and women are weak and vulnerable) to inform their judgments about male and female violence. As a result, perceptions of identical aggressive behaviours vary depending on the gender of the victim and perpetrator (e.g., Seelau \& Seelau, 2005). Hammock, Richardson, Lamm, Taylor, and Verlaque (2017) presented participants four vignettes depicting IPA (male-to-male, female-to-female, male-tofemale, female-to-male) and measured the effect of the victims' and perpetrators' genders on perceptions of the partner aggression. It was found that, regardless of the victim's gender in any given scenario, male perpetrators were perceived more negatively and more likely to cause negative emotions in the victim than female perpetrators. Additionally, regardless of the perpetrator's gender, when female victims were depicted in the vignettes, participants evaluated the perpetrator more negatively and believed the victims were more likely to 
experience negative emotions. These findings suggest that gender plays an important role in informing people's judgements about the acceptability of IPA.

Recent research has suggested that the trivialisation of female aggression may serve to disinhibit women in their use of aggression toward their male partners (Felson et al., 2003; Felson, Savolainen, Hughes, \& Ellonen, 2015). In other words, the expectation that men protect women may result in females believing that their male partners will not retaliate, or that third parties, such as police and onlookers, will intervene to protect them. As a result, women may use aggression against their male partners more readily than men in heterosexual relationships and more readily in other non-intimate situations. Therefore, from this perspective, chivalrous norms are viewed as a risk factor for male victimisation by women. Although, it is beyond the scope of this study to explore the role of sexism in shaping beliefs about IPA, this study explores if gendered approval of IPA exists in the sample population and the role of an individual's beliefs on their use of IPA in heterosexual relationships.

\section{The Effect of Provocation}

Research has shown that provocation, such as insults or physical aggression, is a key factor that elicits interpersonal violence (Berkowitz, 1993; Felson, 1984). If an individual's behaviour is interpreted as offensive or threatening, then the likelihood of the recipient of the behaviour also using physical violence increases (Felson, 1984). It is unsurprising that acceptance of an individual's use of physical aggression varies depending, not only on the gender of the aggressor and recipient, but also on the type of provocation that may have preceded it. For example, research by Forbes, Jobe, White, Bloesch, and Adams-Curtis (2005) found participants justified a person's use of physical violence in response to a sexual betrayal more than non-sexual betrayal, when depicted in vignettes. Indeed, Bettencourt and Miller's (1996) meta-analysis of 64 studies found that the gender differences in general 
aggression were significantly reduced when aggressors experienced provocation. Gender role norms, that deem women's use of violence as undesirable, are thought to inhibit women's use of aggression when they are unprovoked (Bettencourt \& Miller, 1996). This would then lead to lower rates of female violence compared to male violence in these situations. However, when provocation occurs, female aggression is perceived as more justifiable and so women are not constrained by gender role norms (Bettencourt \& Miller, 1996). The authors argue that within intimate relationships there are more opportunities for provocation to occur because couples are interdependent and spend much of their time together. This explains why rates of IPA are symmetrical between men and women compared to other types of violent crimes that are overwhelmingly committed by men (Bettencourt \& Miller, 1996). Thus, provocation may play a particularly important role in IPA. However, despite these findings, very little research has investigated how perceptions of partner violence differ by the type of provocation that occurs. This study will explore the effect of provocation by comparing participants' approval of physical violence across six types of provocation; disobedience, infidelity, psychological aggression, sexual coercion, physical violence, and no provocation. In doing so, it extends previous research that has explored the interaction of participants' approval of IPA by the gender of the perpetrator and victim.

\section{Study Objectives}

Despite a wealth of literature showing the positive relationship between an individual's approval of aggression and their use of aggression, research has not widely investigated this relationship in intimate relationships. Instead, the popular gendered thesis that the aetiology of men's violence towards women is explained by men's approval of aggression towards women prevails. Indeed, this theory drives practice and policy in the area despite a lack of evidence demonstrating the accuracy of this conclusion. 
This study sets out to explore how acceptable a group of heterosexual Western men and women deem IPA to be when gender and provocation are manipulated. It also investigates the relationship between approval ratings of third party IPA and experiences of IPA. Specifically, the following three research questions will be investigated:

1) What are the rates and nature of different forms of IPA used by the male and female university students?

2) To what extent do students approve of aggression by third party heterosexual couples?

3) Do students who self-report perpetrating IPA in the previous 12 months differ in their individual approval ratings of IPA by third parties compared to students who do not selfreport perpetrating IPA?

\section{Method}

\section{Participants}

Participants were male and female students enrolled in first year Psychology at Victoria University of Wellington at the time of the study. Participants had to be at least 17 years of age, and must have had an intimate partner for at least 1 month in their lifetime. Of the 775 who completed the survey, several participants did not meet the inclusion criteria as follows; $3(0.4 \%)$ did not identify their sex as male or female, $60(7.74 \%)$ did not hold Western beliefs, $83(10.71 \%)$ did not identify as heterosexual, $115(14.83 \%)$ had not been in a relationship in the last 12 months, and $55(7.10 \%)$ incorrectly answered one or more attention checks. Finally, $10(1.30 \%)$ participants began but did not complete the questionnaire, and $5(0.70 \%)$ participant responses were not recorded correctly by the system. Some of these categories overlapped for several participants resulting in a final sample size of 515.

The sample consisted of 216 males (41.9\%) and 299 females (58.1\%). Participants reported a mean age of 18.90 years $(S D=2.52)$ and most often identified as New Zealand 
European $(n=345,67.0 \%)$. Additionally, 11.7 percent and 5.2 percent of the sample identified as Maori or Pacifika respectively. At the time of the survey $264(51.3 \%)$ participants were single, $130(25.2 \%)$ were in a stable relationship but not living together, 87 (16.9\%) were dating but not living together, $32(6.25 \%)$ were in a relationship and living together, and two $(0.4 \%)$ were married.

\section{Procedure}

Participants were recruited through the Introduction to Psychology Research (IPRP) scheme hosted by the Victoria University School of Psychology and took part in this online study on a voluntary basis in return for course credits. The study was advertised to students via the Sona System. Participants who were interested in taking part accessed the study information and consent sheet online (see Appendix A). Students were then provided with free helpline numbers in the event they wished to seek further advice about any of the issues discussed, regardless of whether they went on to participate.

Participating students provided informed consent online by checking the appropriate box to indicate consent. Participants were then directed to the Qualtrics survey website where they were presented with a series of online windows containing the study questionnaire. Participants were required to answer each question before moving on to the next. At the end of the questionnaire participants were presented with a debriefing statement (see Appendix B) which thanked them for their time and provided the contact information of relevant services and helplines again. Upon completion of the questionnaire, participants received one credit towards their final grade. To ensure confidentiality, the investigators did not have access to information that could identify participants. The research was approved by the Victoria University School of Psychology Human Ethics Committee before data collection commenced [project \#2254]. 


\section{Measures}

The present study utilised a questionnaire containing four sections that gathered information about demographics, experiences of aggression in relationships, and beliefs about relationship aggression. Halfway through data collection, measures were counterbalanced to control for practice effects. The present study's self-report questionnaire included the following:

\section{Conflict Tactics Scale 2 (CTS-2; Straus, Hamby, Boney-McCoy, \& Sugarman,}

1996). The CTS-2 is designed to assess the tactics that people use during conflict with an intimate partner (negotiation, psychological aggression, physical assault, sexual coercion, or injury). This 78-item self-report questionnaire measures the acts and frequency of negotiation, minor and severe psychological and physical aggression, and minor and severe sexual coercion. Examples of items include; "I slapped my partner", "My partner slapped me", "I destroyed something belonging to my partner", and "My partner destroyed something belonging to me". Participants use a six-point likert scale $(0=$ never to $4=$ very often $)$ to report how often, if at all, they and their intimate partner have used any of the listed acts against each other in the last 12 months $(5=$ this did not happen in the past 12 months but it has happened before).

The CTS-2 has been widely used to assess intimate partner violence in a variety of samples and has acceptable validity and reliability scores in student and non-student populations (Straus, Hamby, Boney-Mcoy, \& Sugarman, 1996). The current study used an adapted version of the traditional CTS-2 scale to simplify responses for students. This has previously been successful in student populations (Archer \& Graham-Kevan, 2003). The Cronbach's alpha for each scale utilised in the current study were as follows: physical assault minor .60 (self) and .72 (partner); physical assault severe .58 (self) and .58 (partner); sexual coercion minor .56 (self) and .61 (partner); sexual coercion severe .57 (self) and .82 (partner); injury minor .20 (self) and .46 (partner); injury severe 1.00 (self) and .78 (partner). 


\section{Controlling Behaviours Scale Revised (CBS-R; Graham-Kevan \& Archer, 2009).}

The CBS-R is a 24-item self-report questionnaire designed to assess the type and frequency of non-physical controlling behaviours used by either member of an intimate couple. Five types of controlling behaviours are examined: economic, threatening, intimidating, emotional, and isolating. Some examples of items included are: "Made it hard to work or study", "Controlled the other's money", "Called the other unpleasant names". Respondents used a six-point likert scale $(0=$ never to $4=$ very often $)$ to rate how often, if at all, they or their partner have used any of the acts in the last 12 months or ever $(5=$ this didn't happen in the past 12 months but it has happened before). The current study used a revised version of the Controlling Behaviours Scale, a measure that has previously been successfully used in a student population (GrahamKevan \& Archer, 2009). Cronbach's alpha was calculated for the five scales: economic .48 (self) and .50 (partner); threatening .32 (self) and .48 (partner); intimidating .46 (self) and .53 (partner); emotional .66 (self) and .72 (partner); isolating .75 (self) and .80 (partner).

Beliefs about Relationship Aggression Scale (BaRAS; Dixon, in preparation). The BaRAS uses brief vignettes to assess the extent respondents approved of physical partner aggression by men and women in heterosexual relationships under different levels of provocation, as well as severity of physically aggressive acts. Each vignette holds all other variables constant while manipulating the independent variables of interest. These are: 1) the sex of the aggressor (two levels: female, male); 2) the level of provocation from the victim (six levels: none, infidelity, minor physical violence, severe physical violence, psychological aggression, and disobedience); 3) the severity of the perpetrator's physical violence (two levels: minor "a slap" or severe "repeatedly punch in the face and body"). This creates a 2x6x2 factorial design, and thus 24 vignettes are used in total to capture all of the independent variables. For each vignette, five questions are asked to gain a broad measure of their approval of the aggression and beliefs about likelihood of harm to the victim. This results in a total of 
120 question. The questionnaire is introduced by explaining that each vignette involves an averaged sized man and woman who are involved in a monogamous relationship to ensure a neutral context is provided for the participant. An example of a vignette and the five standard accompanying questions is provided below. The example below depicts a male aggressor and female victim, infidelity as provocation, and minor severity of physical violence.

Example: John discovered that Carol was having an affair with another man. One evening when Carol was sat on the sofa watching television he confronted her about her infidelity and slapped her across the face.

a) To what extent do you approve of [the aggressor's] actions?

b) How likely is it that [the victim] will be physically injured, requiring medical treatment?

c) How likely is that [the victim] will be greatly emotionally distressed?

d) How likely it is that [the victim] can defend themselves against [the aggressor]?

e) Which legal sanction they deem as suitable punishment for [the aggressor]?

For the purpose of this study, responses to questions ' $a$ ' were analysed to gain an understanding of participants' approval of aggressive actions when various provocations occur. Cronbach's alpha was calculated for three scales: approval of aggression used by a male .84; approval of aggression used by a female .79; approval of aggression regardless of the aggressor's gender .88 .

\section{Treatment of Data}

Research question one. To explore the rates and nature of IPA that participants used and experienced, the following manipulations were made to the data. The original CTS-2 and CBS-R measures recorded participant responses on a $0-5$-point scale $(0=$ never happened to 4 $=$ has happened very often in the past 12 months, and $5=$ this didn't happen in the past 12 months but it has happened before). For the purpose of analysis this data was dichotomised to 
demonstrate participants who had experienced and used the tactics of interest in the 12 months prior to completing the questionnaire and those who had not $(0=$ never happened and $1=$ has in the last 12 months). Chi square analysis was computed separately for men and women to identify significant differences in the frequency participants reported experiencing, as well as reported using, each tactic measured on the CTS-2 and CBS-R. Chi squared was also computed separately for reports of using and reports of experiencing each tactic to identify significant differences between males and females. Effect sizes were computed using Phi to determine the magnitude of the significant results. An effect size of $1.0-0.5$ indicated a strong association, while an effect size of $0.5-0.3$ indicated a moderate association. Finally, an effect size of 0.3 - 0.1 signaled a weak association (Tabachnick, Fidell, \& Osterlind, 2001)

Chi square requires that the expected count in each cell is greater than 5 (Field, 2013). This assumption was violated for some tests and in these instances Fisher's exact statistic was interpreted. The assumption of independence of data was met as each item only contributed to one cell on the contingency table (Field, 2013).

Research question two. Items concerning approval of aggression in the BaRAS questionnaire were analysed to determine how acceptable participants perceived IPA to be when used in response to various provocation levels by men and women. To answer this research question, four sub-questions were developed and analysed separately, therefore treatment of data will be presented for each in turn.

\section{a) What impact does provocation have on participants' approval of IPA? To}

understand the overall impact provocation type had on participants' mean approval of IPA, scores obtained from the BaRAS questions regarding approval of minor and severe aggression were added together to produce two scales depicting 'approval of any IPA' used by either a male or female separately. Total approval scores ranged from $1-5$ for each participant. The approval scores for male and female aggression were then combined and 
divided by two. This created a scale which depicted each participant's "approval of any IPA used by both men and women" with scores ranging from 1 to 5 . A one-way repeated measures ANOVA was then computed to determine whether approval varied by provocation type (six levels). The effect sizes were calculated using partial eta squared with 0.01 signalling a small effect size, 0.09 indicating a medium effect and 0.25 a large effect. Pairwise comparisons determined where the significant differences lay.

The assumption of normality was violated for all scales concerning approval of aggression. This was expected as most of the general population do not approve of aggression. ANOVA is robust to variations from normality when group sizes are greater than 40 and are relatively equal, as is the case with the current sample, therefore analysis continued (Field, 2013).

b) How does the gender of the participant impact approval of IPA? The scale depicting "approval of any IPA used by both men and women" was utilised to determine whether approval of IPA, across various provocation types, differed by the participant's gender. A 2x6 mixed ANOVA was conducted with provocation (six levels) as the within subjects factor and participant's gender (two levels) as the between subjects factor. Post hoc tests were completed using one-way between subjects ANOVAs to determine whether approval of IPA differed between male and female participants at each level of provocation. The Bonferroni correction was applied to correct for type 1 error resulting in a new alpha value of 0.008 (Field, 2013). To identify differences in approval between provocation levels post hoc one-way repeated measures ANOVAs were run separately for men and women. Pairwise comparisons determined where significant differences lay.

Levene's test signalled that, when provocation occurred in the form of physical violence, the assumption of homogeneity of variance was violated in the 2x6 ANOVA ( $F$ (1, $513)=6.14, p=.014)$. However, when sample sizes are relatively equal, ANOVA is robust to 
violation of homogeneity of variance (Field, 2013). Therefore, analysis continued. Maulchy's test indicated that the assumption of specificity had been violated $(\chi 2(14)=0.070, p>.001)$. Therefore, degrees of freedom were corrected using Greenhouse-Geisser estimates of specificity $(\varepsilon=0.624)$.

\section{c) Does the gender of the aggressor in the vignette have an impact on approval of}

IPA? To determine whether approval of IPA, in the context of various provocation types, differed by aggressor's gender, scales depicting "approval of any IPA used by a male" and "approval of IPA used by a female"” aggressor were used. Considering the study design utilised two within subjects factors; (provocation [6 levels] and gender of aggressor [2 levels]), differences in approval ratings were analysed using a 6x2 repeated measures ANOVA. Post hoc one-way ANOVAs were completed to explore how approval differed when aggression was perpetrated by a man or a woman, at each provocation level. The Bonferroni correction was applied to correct for type 1 errors resulting in a new alpha value of 0.008 . To identify differences in approval between provocation levels post hoc one-way repeated measures ANOVAs were run separately for when the vignette presented a male aggressor and a female aggressor. Pairwise comparisons were used to determine where the differences lay.

Maulchy's test indicated the assumption of specificity was violated for provocation by aggressors gender $(\chi 2(14)=0.403, p>.001)$. Therefore, degrees of freedom were corrected using Greenhouse-Geisser estimates of specificity $(\varepsilon=0.80)$.

\section{d) Is the relationship between provocation type and the aggressor's gender}

influenced by the gender of the participant? To determine whether the participant's gender influenced the interaction between provocation and aggressor's gender, a 3-way 2x2x6 ANOVA was computed. Within subjects factors included approval of aggression (two levels: male aggressor and female aggressor) and provocation (6 levels: psychological aggression, disobedience, physical violence, infidelity, sexual coercion and no provocation), while the 
participant's gender (two levels: male and female) was utilised as the between subjects factor. Post hoc tests were completed using one-way repeated measures ANOVAs and one-way between subjects ANOVAs. The Bonferroni correction was applied, resulting in a new alpha value of 0.083 .

Levene's test indicated that the assumption of homogeneity of variance was violated when a male aggressor was provoked by physical violence $(F(1,513)=11.93, p=.001)$. However, as previously discussed, ANOVA is robust to unequal variance when group sample sizes are greater than 40 and relatively equal. Mauchly's test indicated that the assumption of specificity was violated $\left(\chi^{2}(14)=0.065, p>.001\right)$. Therefore, degrees of freedom were corrected using Greenhouse-Geisser estimates of specificity $(\varepsilon=0.624)$.

Research Question Three. Differences in the approval of aggression scores of participants who had perpetrated physical aggression were compared to those who had not. Participants were allocated into one of two categories (aggressive or non-aggressive) depending on their self-reports of using minor and/or severe physical violence in the 12 months prior to completing the questionnaire. Using the binary scales devised from the CTS-2 (detailed above), reports of severe and minor physical aggression were added together and divided by two resulting in a "use of any IPA" scale with potential scores ranging from 1-5. Approval of IPA across each provocation type were added together and divided by 6 (i.e. the number of provocation types). This occurred separately for "approval of male aggression" and "approval of female aggression" in the vignettes, resulting in two scales with potential scores ranging from 1-5.

A mixed three-way $2 \times 2 \times 2$ ANOVA was computed to identify how approval of IPA differed between participants that used IPA in the 12 months prior to completing the survey (aggressive) and those who did not (non-aggressive). Approval of aggressors' gender (male or 
female) formed the within subjects factor, while the participant's gender (male or female) and IPA status (aggressive or non-aggressive) were between subjects factors.

\section{Results}

\section{Research Question One: What are the rates and nature of different forms of IPA used by male and female university students?}

Table 1 depicts the frequency at which participants reported using and experiencing the various tactics depicted in the CBS-R and CTS-2 scales in the 12 months prior to completing the questionnaire. Table 2 depicts the results of statistical analysis that shows the differences between the use and experience of the CBS-R and CTS-2 tactics, separately for men and women.

The majority of CBS-R tactics were used and experienced at approximately equal rates by both men and women, with few significant differences. Chi square demonstrated a significant difference in the frequency that women used and experienced threatening behaviours, with women being significantly more likely to report using this behaviour than experiencing it $\left(\chi^{2}(1)=4.03, p=.05, \varphi=-0.08\right)$. No other significant differences were found between females use and experiences of the CBS-R tactics. Chi square found no significant differences in the frequency of CBS-R tactics used and experienced by male participants.

The majority of CTS-2 tactics were also used and experienced at approximately equal rates by both men and women, with few significant differences found. Chi square demonstrated a significant difference in the frequency of minor physical aggression, with females reporting they used this tactic more than they experienced it $\left(\chi^{2}(1)=5.22, p=.02, \varphi\right.$ $=-0.09)$. Females were significantly more likely to experience both minor $\left(\chi^{2}(1)=14.54, p<\right.$ $.001, \varphi=0.16)$ and severe sexual coercion $\left(\chi^{2}(1)=4.54, p=.03, \varphi=0.08\right)$ than to use these 
acts against male partners. For men, chi square demonstrated a significant difference in the frequency of experiencing severe physical assault, with men being significantly more likely to report experiencing this behaviour than using it $\left(\chi^{2}(1)=4.99, p=.03, \varphi=-0.11\right)$. Finally, a significant difference in the frequency of men's minor injury was found. Men were significantly more likely to report experiencing minor injury than causing it $\left(\chi^{2}(1)=7.55, p\right.$ $=.01, \varphi=-0.13)$. Although significant differences were found, it is interesting to note that the effect size for all differences signalled a weak association.

Table 3 depicts the difference between men and women's use and experience of various tactics presented in the CTS- 2 and the CBS-R in the 12 months prior to completing the questionnaire. The majority of acts were used and experienced at approximately equal rates between men and women, with few significant differences found. Chi square demonstrated a significant difference between men and women in the frequency of: threatening behaviours used, with women using this tactic more often than men $\left(\chi^{2}(1)=7.04, p=.01, \varphi=0.12\right)$, severe physical assault, with more women using this tactic more than men $\left(\chi^{2}(1)=4.25, p=\right.$ $.04, \varphi=0.09)$, minor sexual coercion used, with men reporting the use of this tactic more often than women $\left(\chi^{2}(1)=6.51, p=.01, \varphi=-0.11\right)$; and experiences of minor physical assault, with men reporting they experienced this tactic more than women $\left(\chi^{2}(1)=3.97, p=\right.$ $.05, \varphi=0.09)$. These were the only significant differences found between men's and women's experiences, with all differences signalling weak effect sizes. Therefore, results suggest on the whole that aggressive acts are experienced at approximately equal rates by both genders. 
Table 1

The frequency of tactics used and experienced by men and women during times of conflict with their intimate partner in the 12 months prior to completing the questionnaire $(N=515)$

Frequency of tactics used Frequency of tactics experienced

Used by men Used by women Experienced by Experienced by

$N(\%) \quad N(\%) \quad$ men $N(\%) \quad$ women $N(\%)$

\section{Controlling Behaviours Scale}

$\begin{array}{lcccc}\text { Economic } & 178(82.4) & 230(76.9) & 185(85.6) & 237(79.3) \\ \text { Threatening } & 69(31.9) & 130(43.5) & 81(37.5) & 106(35.5) \\ \text { Intimidating } & 102(47.2) & 147(49.2) & 106(49.1) & 152(50.8) \\ \text { Emotional } & 129(59.7) & 193(64.5) & 129(59.7) & 185(61.9) \\ \text { Isolating } & 164(75.9) & 234(78.3) & 177(81.9) & 220(73.6)\end{array}$

\section{Conflict Tactics Scale}

Physical Assault

$\begin{array}{lllll}\text { Minor } & 71(32.9) & 108(36.1) & 77(35.6) & 82(27.4) \\ \text { Severe } & 12(5.6) & 32(10.7) & 25(11.6) & 26(8.7)\end{array}$

Injury

Minor

$4(1.9)$

$12(4.0)$

$16(7.4)$

$16(5.4)$

Severe

$1(0.5) \quad 0(0)$

$2(0.9)$

$1(0.3)$

\section{Sexual Coercion}

$\begin{array}{lllll}\text { Minor } & 79(36.6) & 78(26.1) & 79(36.6) & 122(40.8) \\ \text { Severe } & 4(1.9) & 2(0.7) & 4(1.9) & 9(3.0)\end{array}$

Note: $* * p<.001,{ }^{*} p<.05$ 
Table 2

Differences between tactics used and experienced by men and by women separately during times of conflict with their intimate partner in the 12 months prior to completing the questionnaire $(N=515)$

\begin{tabular}{llll}
\hline \multicolumn{2}{l}{ Men $(\boldsymbol{n}=\mathbf{2 1 6})$} & Women $(\boldsymbol{n}=\mathbf{2 9 9})$ \\
\hline Chi Square & Phi & Chi Square & Phi \\
Statistic & & Statistic & \\
\hline
\end{tabular}

Controlling Behaviours Scale

Economic

0.85

0.04

0.48

$-0.03$

$p=.36$

$p=.49$

Threatening

1.47

0.06

4.03

$-0.08$

$p=.23$

$p=.05^{*}$

Intimidating

.15

0.02

0.17

0.02

$p=.70$

$p=.68$

Emotional

0.00

0.00

0.46

$p=1.0$

$p=.50$

Isolating

\subsection{5}

0.07

1.79

$-0.06$

$p=.13$

$p=.18$

\section{Conflict Tactics Scale}

\section{Physical Assault}

Minor

$$
0.37
$$

0.03

5.22

$-0.09$

$p=.54$

$p=.02 *$

Severe

$$
4.99
$$

0.11

.69

$-0.03$

$$
p=.03 *
$$

$p=.41$ 


\section{Injury}

Minor

7.55

0.13

0.60

0.03

$p=.01^{*}$

$p=.44$

Severe

$\mathrm{FE}=1.0 \quad 0.03$

$\mathrm{FE}=1.0$

0.04

\section{Sexual Coercion}

Minor

0.00

0.00

14.54

0.16

$p=1.00$

$p=.000 * *$

Severe

$\mathrm{FE}=1.0 \quad 0.00$

4.54

0.08

$p=.03^{*}$

Note: $* * p<.001, * p<.05$

Table 3

The difference between men's and women's use and experience of various tactics during times of conflict with their intimate partner in the 12 months prior to completing the questionnaire $(N=515)$

\begin{tabular}{lllll}
\hline & Used & \multicolumn{3}{c}{ Experienced } \\
& Chi Square & Phi & Chi Square & Phi \\
& Statistic & & Statistic & \\
& \multicolumn{4}{c}{ Controlling Behaviours Scale } \\
Economic & 2.29 & -0.07 & 3.45 & -0.08 \\
& $p=.13$ & & $p=.06$ & \\
Threatening & 7.04 & 0.12 & 0.23 & -0.02 \\
& $p=.01 *$ & & $p=.63$ & 0.02 \\
\hline
\end{tabular}


$p=.66$

Emotional

$p=.25$

Isolating

0.39

$p=.53$ $p=.69$

0.24

0.02

$p=.62$

4.97

$-0.10$

$p=.03$

\section{Conflict Tactics Scale}

\section{Physical Assault}

Minor

0.58

0.03

3.97

$-0.09$

$p=.03$

$p=.05^{*}$

Severe

4.25

0.09

1.17

$-0.05$

$p=.04^{*}$

$p=.28$

\section{Injury}

Minor

1.95

0.06

0.91

$-0.04$

$p=.16$

$p=.34$

Severe

$\mathrm{FE}=0.42$

$-0.05$

$\mathrm{FE}=0.58$

$-0.04$

Sexual Coercion

Minor

6.51

$-0.11$

0.94

0.04

$$
p=.01 *
$$

$$
p=.33
$$

Severe

$$
\mathrm{FE}=0.24
$$

$-0.05$

0.68

0.04

$$
p=.41
$$

Note: $* * p<.001, * p<.05$ 


\section{Research Question Two: To what extent do students approve of aggression by third party heterosexual couples?}

a) What impact does provocation have on participants' mean approval of IPA? Figure 1 demonstrates participants' (men and women combined) mean approval of physical aggression (a slap or punch) used in response to various types of provocation, as presented in the BaRAS vignettes. A repeated measures one-way ANOVA was run to explore how approval differed between various provocation types (disobedience, infidelity, psychological aggression, sexual coercion, physical violence, and no provocation). Results revealed a significant effect of provocation on approval $\left(F(5,1561.80)=369.33, p<.001, \eta_{\mathrm{p}}{ }^{2}=.42\right)$. The partial eta squared value of .42 indicates a large effect size. As depicted in Table 4, significant differences were found between all provocation levels except; disobedience and no provocation (mean difference of -0.001), and infidelity and sexual coercion (mean difference of 0.002). These findings indicate that approval of IPA significantly differed by provocation type. Mean scores showed that the highest level of approval occurred in response to physical violence $(M=1.91, S D=0.74)$, while the lowest level of approval was found when no provocation occurred $(M=1.10, S D=0.30)$ and when provocation occurred in the form of disobedience $(M=1.04, S D=0.01)$. 


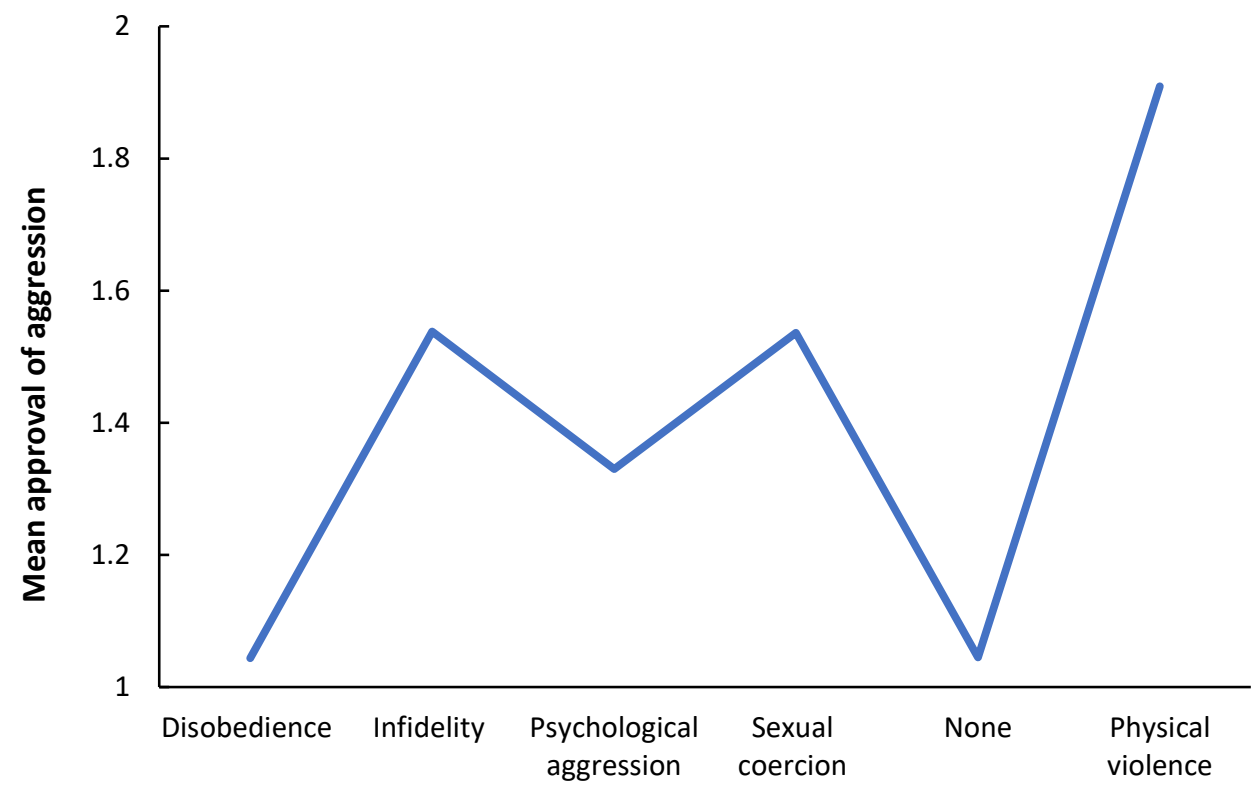

\section{Provocation level}

Figure 1. The mean approval of any aggression used in the BaRAS vignettes, by males and females, in response to various types of provocation $(N=515)$ 
Table 4

Pairwise comparisons; mean differences in approval of physical aggression, used by men and women, in response to various types of provocation $(N=515)$

\begin{tabular}{|c|c|c|c|c|c|}
\hline Provocation type & Provocation comparison level & Mean difference & Standard error & $p$ value & Cohens d \\
\hline \multicolumn{6}{|c|}{ Repeated measures one-way ANOVA: $F(3.04,1561.80)=369.33, p<.001 * *$} \\
\hline \multirow[t]{5}{*}{ Disobedience } & Infidelity & -.494 & .025 & $.001 * *$ & -1.07 \\
\hline & Psychological aggression & -.286 & .019 & $.001 * *$ & -0.74 \\
\hline & Sexual coercion & -.492 & .022 & $.001 * *$ & -1.24 \\
\hline & None & -.001 & .006 & .792 & -0.01 \\
\hline & Physical violence & -.866 & .032 & $.001 * *$ & -1.56 \\
\hline \multirow[t]{4}{*}{ Infidelity } & Psychological aggression & .208 & .019 & $.001 * *$ & 0.60 \\
\hline & Sexual coercion & .002 & .026 & .941 & 0.54 \\
\hline & None & .493 & .025 & $.001 * *$ & 1.05 \\
\hline & Physical violence & -.371 & .027 & $.001 * *$ & 0.02 \\
\hline \multirow[t]{3}{*}{ Psychological aggression } & Sexual coercion & -.206 & .024 & $.001 * *$ & 0.19 \\
\hline & None & .285 & .019 & $.001 * *$ & 0.72 \\
\hline & Physical violence & -.579 & .026 & $.001 * *$ & -0.31 \\
\hline \multirow[t]{2}{*}{ Sexual coercion } & None & .491 & .022 & $.001 * *$ & 1.21 \\
\hline & Physical violence & -.373 & .032 & $.001 * *$ & 0.01 \\
\hline None & Physical violence & -.864 & .032 & $.001 * *$ & -0.86 \\
\hline
\end{tabular}

Note: $* * p<.001$ 
b) How does the gender of the participant impact approval of IPA? To assess whether the observed trend of approval in Figure 1 was impacted by the gender of the participant, a 2x6 mixed ANOVA was conducted. Figure 2 depicts separately, male and female participants' mean approval of IPA used in the context of different provocation levels, as presented in the BaRAS vignettes. A significant interaction was found between the participant's gender and provocation $(F(3.12,5968.52)=16.90, p<.001, \eta p 2=.03, \varepsilon=$ 0.624). The partial eta squared value of .03 indicates a small effect size. Figure 2 depicts the interaction plot.

To unpack the interaction further, six separate post hoc one-way between subjects ANOVAs were computed to determine whether approval of aggression differed significantly between male and female participants at each level of provocation, as shown in Table 5. Using the Bonnferoni corrected alpha statistic of .008, a significant difference in the mean approval of IPA was found between men and women when provocation occurred in the form of physical violence, with men holding more approval $(M=2.12)$ than females $(M=1.80)$. No other significant differences were found (see table 5 below). These findings indicate that men and women hold similar levels of approval with regards to IPA, except in situations where the aggressor is provoked with physical violence. In this situation males approved more of IPA than females.

Although not the primary focus of this research question, it is noteworthy that within gender analysis showed a similar pattern of mean scores across provocation levels as analysis of the total sample (see Figure 1). Post hoc one-way repeated measures ANOVAs were run separately for men and women. It was found that, for men, a significant effect of provocation was found $\left(F(3.10,655.30)=216.50, p<.001, \eta_{\mathrm{p}}^{2}=.50, \varepsilon=0.610\right)$. Similar to the whole sample, mean scores for male participants showed that the highest level of approval occurred 
in response to physical violence $(M=2.12, S D=0.80)$, while the lowest level of approval was found when no provocation occurred $(M=1.04, S D=0.20)$ or disobedience occurred $(M$ $=1.04, S D=0.14)$. Pairwise comparisons revealed significant differences between all provocation levels except; disobedience and no provocation (mean difference of 0.00 ), and infidelity and sexual coercion (mean difference of 0.10 ; see Table 6)

For women, ANOVA also showed a significant effect of provocation $(F(3.10,907.83)=$ $\left.170.33, p<.001, \eta_{\mathrm{p}}^{2}=.40\right)$. Maulchy's test indicated the assumption of specificity was violated $\left(\chi^{2}(14)=0.062, p>.001\right)$. Therefore, degrees of freedom were corrected using Greenhouse-Geisser estimates of specificity $(\varepsilon=0.616)$. Mean scores showed that, for female participants, the highest level of approval occurred in response to physical violence $(M=$ $1.80, S D=0.70)$, while the lowest level of approval was found when no provocation $(M=$ $1.10, S D=0.32)$ or disobedience occurred $(M=1.10, S D=0.30)$. Pairwise comparisons revealed significant differences between all provocation levels except; disobedience and no provocation (mean difference of -0.03), and infidelity and sexual coercion (mean difference of -0.12 ; see Table 7). 


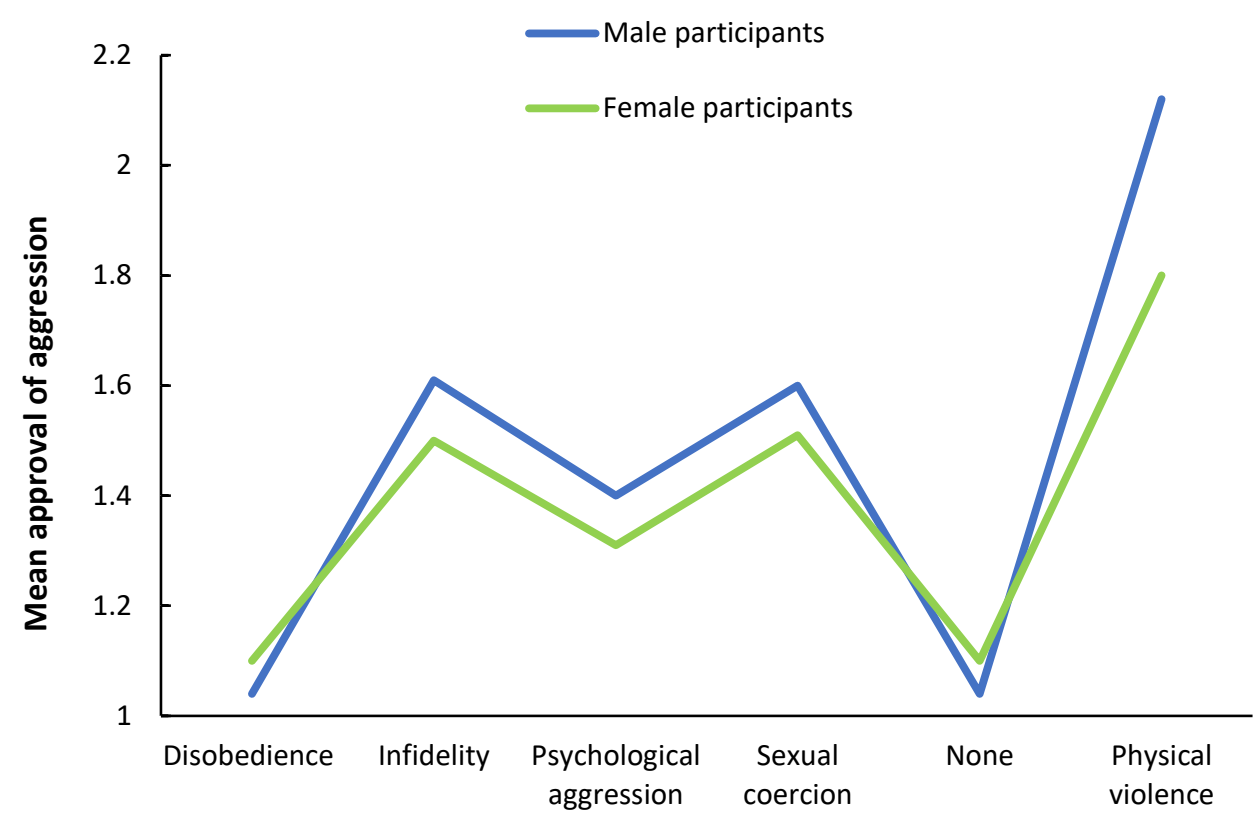

Provocation level

Figure 2. Male and female participants' mean approval of any IPA depicted in the BaRAS vignettes $(N=515)$ 
Table 5

Male $(n=216)$ and female $(n=299)$ participants' mean approval of physical aggression used in response to various types of provocation, as presented in the BARAS vignettes

Approval of Aggression Ratings

\begin{tabular}{|c|c|c|c|c|c|}
\hline & \multicolumn{2}{|c|}{$\begin{array}{l}\text { Male } \\
\text { participants }\end{array}$} & \multicolumn{2}{|c|}{$\begin{array}{l}\text { Female } \\
\text { participants }\end{array}$} & \multirow[t]{2}{*}{ One-way ANOVAs } \\
\hline & Mean & SD & Mean & SD & \\
\hline \multicolumn{6}{|l|}{ Provocation type } \\
\hline Disobedience & 1.04 & 0.14 & 1.10 & 0.30 & $\begin{array}{l}\left(F(1,513)=.182, p=.670, \eta_{\mathrm{p}}^{2}=\right. \\
.00)\end{array}$ \\
\hline Infidelity & 1.61 & 0.60 & 1.50 & 0.60 & $\begin{array}{l}\left(F(1,513)=5.900, p=.020, \eta_{\mathrm{p}}^{2}\right. \\
=.011)\end{array}$ \\
\hline $\begin{array}{l}\text { Psychological } \\
\text { aggression }\end{array}$ & 1.40 & 0.42 & 1.31 & 0.53 & $\begin{array}{l}\left(F(1,513)=1.900, p=.202, \eta_{\mathrm{p}}^{2}\right. \\
=.004)\end{array}$ \\
\hline Sexual coercion & 1.60 & 0.50 & 1.51 & 0.52 & $\begin{array}{l}\left(F(1,513)=1.321, p=.301, \eta_{\mathrm{p}}^{2}\right. \\
=.003)\end{array}$ \\
\hline None & 1.04 & 0.20 & 1.10 & 0.32 & $\begin{array}{l}\left(F(1,513)=.244, p=.622, \eta_{\mathrm{p}}^{2}=\right. \\
.00)\end{array}$ \\
\hline Physical violence & 2.12 & 0.80 & 1.80 & 0.70 & $\begin{array}{l}(F(1,513)=32.500, p<.001 * * \\
\left.\eta_{\mathrm{p}}{ }^{2}=.06\right)\end{array}$ \\
\hline
\end{tabular}

Note: $* * p<.001$, Bonferoni corrected $\alpha=.008$ 
Table 6

Pairwise comparisons; male participants' mean differences in the approval of physical aggression used in response to various types of provocation $(n=216)$

\begin{tabular}{|c|c|c|c|c|c|}
\hline Provocation level & Provocation comparison level & Mean difference & Standard error & $p$ value & Cohens d \\
\hline \multicolumn{6}{|c|}{ Repeated measures one-way ANOVA: $F(3.04,1561.80)=369.33, p<.001 * *$} \\
\hline \multirow{5}{*}{ Disobedience } & Infidelity & -.575 & .039 & $.001 * *$ & -1.31 \\
\hline & Psychological aggression & -.326 & .026 & $.001 * *$ & -1.04 \\
\hline & Sexual coercion & -.528 & .032 & $.001 * *$ & -1.50 \\
\hline & None & .000 & .009 & 1.000 & 0.00 \\
\hline & Physical violence & -1.084 & .051 & $.001 * *$ & -1.98 \\
\hline \multirow[t]{4}{*}{ Infidelity } & Psychological aggression & .249 & .032 & $.001 * *$ & 0.48 \\
\hline & Sexual coercion & .047 & .044 & .279 & 0.09 \\
\hline & None & .575 & .040 & $.001 * *$ & 1.29 \\
\hline & Physical violence & -.509 & .048 & $.001 * *$ & -0.74 \\
\hline \multirow[t]{3}{*}{ Psychological aggression } & Sexual coercion & -.201 & .037 & $.001 * *$ & -0.45 \\
\hline & None & .326 & .027 & $.001 * *$ & 1.00 \\
\hline & Physical violence & -.758 & .044 & $.001^{* *}$ & -1.23 \\
\hline \multirow[t]{2}{*}{ Sexual coercion } & None & .528 & .033 & $.001 * *$ & 1.46 \\
\hline & Physical violence & -.557 & .052 & $.001 * *$ & -0.88 \\
\hline None & Physical violence & -1.084 & .052 & $.001 * *$ & -1.95 \\
\hline
\end{tabular}

Note: $* *=p<.001$ 
Table 7

Pairwise comparisons; female participants' mean differences in the approval of physical aggression used in response to various types of provocation $(n=299)$

\begin{tabular}{|c|c|c|c|c|c|}
\hline Provocation level & Provocation comparison level & Mean difference & Standard error & $p$ value & Cohens d \\
\hline \multicolumn{6}{|c|}{ Repeated measures one-way ANOVA: $F(3.04,1561.80)=369.33, p<.001^{* *}$} \\
\hline \multirow[t]{5}{*}{ Disobedience } & Infidelity & -.436 & .032 & $.001 * *$ & -0.92 \\
\hline & Psychological aggression & -.258 & .026 & $.001 * *$ & -0.60 \\
\hline & Sexual coercion & -.467 & .029 & $.001 * *$ & -1.09 \\
\hline & None & -.003 & .007 & .719 & -0.01 \\
\hline & Physical violence & -.707 & .039 & $.001 * *$ & -1.32 \\
\hline \multirow[t]{4}{*}{ Infidelity } & Psychological aggression & .178 & .023 & $.001 * *$ & 0.32 \\
\hline & Sexual coercion & -.031 & .032 & .340 & -0.05 \\
\hline & None & .433 & .031 & $.001 * *$ & 0.90 \\
\hline & Physical violence & -.272 & .030 & $.001 * *$ & -0.42 \\
\hline \multirow[t]{3}{*}{ Psychological aggression } & Sexual coercion & -.209 & .031 & $.001 * *$ & -0.40 \\
\hline & None & .255 & .026 & $.001 * *$ & 0.58 \\
\hline & Physical violence & -.450 & .028 & $.001 * *$ & -0.73 \\
\hline \multirow[t]{2}{*}{ Sexual coercion } & None & .464 & .029 & $.001 * *$ & 1.07 \\
\hline & Physical violence & -.241 & .039 & $.001 * *$ & -0.39 \\
\hline None & Physical violence & -.705 & .038 & $.001 * *$ & -1.31 \\
\hline
\end{tabular}

Note: $* *=p<.001$ 
c) Does the gender of the aggressor in the vignette have an impact on approval of

IPA? To assess the impact that the aggressor's gender in the vignette (male or female) has on approval across various provocation types, a repeated measures $6 \times 2$ ANOVA was computed as shown in Figure 3. A significant interaction was found between aggressor's gender and provocation $(F(3.04,1936.60)=184.51, p<.001, \eta p 2=.30, \varepsilon=0.80)$. The partial eta squared value of .30 indicates a large effect size. Figure 3 depicts the interaction plot.

Six separate post hoc one-way ANOVAs were computed to determine whether approval of male and female aggression in the vignettes differed significantly at each level of provocation; as presented in Table 3 below. The results indicated that the gender of the aggressor significantly impacted approval ratings. Participant's approved of female aggression significantly more than male aggression in the majority of provocation levels (psychological, physical, infidelity and sexual coercion). No significant difference in approval was found between male and female aggression when the provocation was disobedience or when no provocation occurred (see Table 8). Although not the focus of the current research question, two post hoc repeated measures ANOVAs were run separately for vignettes that presented a male aggressor and a female aggressor. When the aggressor in the vignette was a female, the pattern of approval differed slightly from that found for approval of male and female aggressors combined (see Figure 1). Pairwise comparisons (see Table 9) revealed significant differences between all provocation levels except; disobedience and no provocation (mean difference of 0.01 ). Whereas approval for male and female aggressors combined also found differences between infidelity and sexual coercion (see Table 4). When the aggressor in the vignette was a male, the pattern of approval also differed slightly from that found for both male and female aggressors combined (see Figure 1). Pairwise comparisons (see Table 10) revealed significant differences between all provocation levels 
except; disobedience and no provocation (mean difference of 0.50 ) and psychological aggression and sexual coercion (mean difference of 0.03 ). When approval of male and female aggression was combined, no difference was found between psychological aggression and sexual coercion, but instead differences were found between infidelity and sexual coercion (see Table 4). 


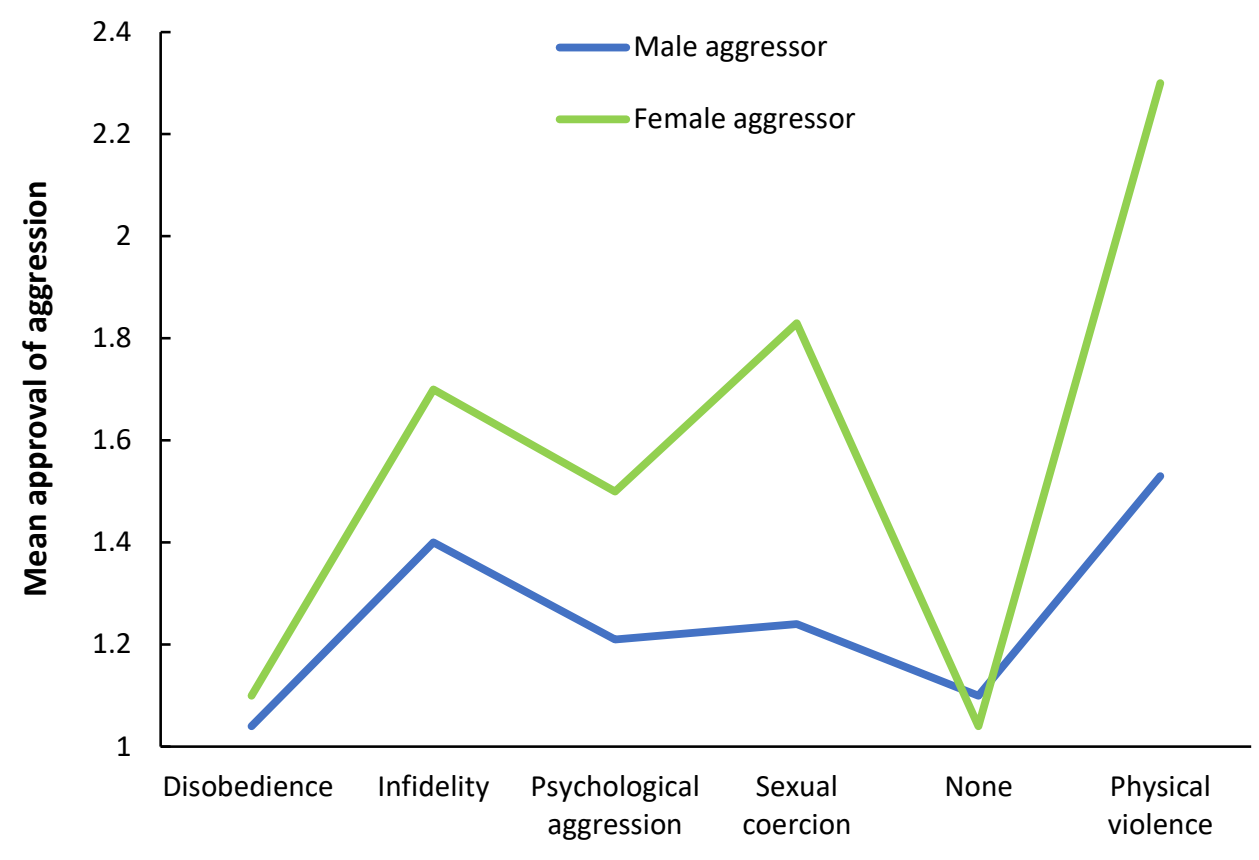

Provocation level

Figure 3. The mean approval of physical aggression (a slap or punch) used by either and man or a woman in response to various types of provocation in the BaRAS vignette $(\mathrm{N}=515)$ 
Table 8

The mean approval of physical aggression used by either a man or a woman in response to various types of provocation, as presented in the BARAS vignettes

\section{Approval of Aggression Ratings}

\begin{tabular}{|c|c|c|c|c|c|}
\hline & \multicolumn{2}{|c|}{ Male aggressor } & \multicolumn{2}{|c|}{ Female aggressor } & \multirow[t]{2}{*}{ One-way ANOVAs } \\
\hline & Mean & $S D$ & Mean & $S D$ & \\
\hline Provocation type & & & & & \\
\hline Disobedience & 1.04 & 0.26 & 1.10 & 0.29 & $\begin{array}{l}(F(1,514)=1.201, p= \\
\left..300, \eta_{\mathrm{p}}^{2}=.002\right)\end{array}$ \\
\hline Infidelity & 1.40 & 0.59 & 1.70 & 0.74 & $\begin{array}{l}(F(1,514)=147.403, p< \\
\left..001^{* *}, \eta_{\mathrm{p}}^{2}=.22\right)\end{array}$ \\
\hline $\begin{array}{l}\text { Psychological } \\
\text { aggression }\end{array}$ & 1.21 & 0.46 & 1.50 & 0.63 & $\begin{array}{l}(F(1,514)=124.613, p< \\
\left..001^{* *}, \eta_{\mathrm{p}}^{2}=.20\right)\end{array}$ \\
\hline Sexual coercion & 1.24 & 0.44 & 1.83 & 0.74 & $\begin{array}{l}(F(1,514)=387.120, p< \\
\left..001^{* *}, \eta_{\mathrm{p}}^{2}=.43\right)\end{array}$ \\
\hline None & 1.10 & 0.30 & 1.04 & 0.28 & $\begin{array}{l}(F(1,514)=.302, p= \\
\left..620 \eta_{\mathrm{p}}^{2}=.000\right)\end{array}$ \\
\hline Physical violence & 1.53 & 0.67 & 2.30 & 1.01 & $\begin{array}{l}(F(1,514)=406.600, p< \\
\left..001^{* *}, \eta_{\mathrm{p}}{ }^{2}=.44\right)\end{array}$ \\
\hline
\end{tabular}

Note: $* * p<.001$, Bonfferoni corrected $\alpha=0.008$ 
Table 9

Pairwise comparisons; mean differences in the approval of physical aggression used in response to various types of provocation when the aggressor is a female $(N=515)$

\begin{tabular}{|c|c|c|c|c|c|}
\hline Provocation level & Provocation comparison level & Mean difference & Standard error & $p$ value & Cohen d \\
\hline \multicolumn{6}{|c|}{ Repeated measures one-way ANOVA: $F(5,1623.403)=390.500, p<.001^{* *}$} \\
\hline \multirow[t]{5}{*}{ Disobedience } & Infidelity & -.647 & .031 & $.001 * *$ & -1.14 \\
\hline & Psychological aggression & -.404 & .025 & $.001 * *$ & -0.83 \\
\hline & Sexual coercion & -.784 & .034 & $.001 * *$ & -1.40 \\
\hline & None & .007 & .009 & .468 & 0.02 \\
\hline & Physical violence & -1.242 & .045 & $.001 * *$ & -1.67 \\
\hline \multirow[t]{4}{*}{ Infidelity } & Psychological aggression & .243 & .026 & $.001 * *$ & 0.35 \\
\hline & Sexual coercion & -.138 & .037 & $.001 * *$ & -0.19 \\
\hline & None & .653 & .032 & $.001 * *$ & 1.16 \\
\hline & Physical violence & -.595 & .037 & $.001 * *$ & -0.67 \\
\hline \multirow[t]{3}{*}{ Psychological aggression } & Sexual coercion & -.381 & .036 & $.001 * *$ & -0.56 \\
\hline & None & .411 & .026 & $.001 * *$ & 0.85 \\
\hline & Physical violence & -.838 & .038 & $.001 * *$ & -1.00 \\
\hline \multirow[t]{2}{*}{ Sexual coercion } & None & .791 & .034 & $.001 * *$ & 1.41 \\
\hline & Physical violence & -.457 & .046 & $.001 * *$ & -0.52 \\
\hline None & Physical violence & -1.249 & .045 & $.001 * *$ & -1.68 \\
\hline
\end{tabular}

Note: $* *=p<.001$ 
Table 10

Pairwise comparisons; mean differences in the approval of physical aggression used in response to various types of provocation when the aggressor is a male $(N=515)$

\begin{tabular}{|c|c|c|c|c|c|}
\hline Provocation level & Provocation comparison level & Mean difference & Standard error & $p$ value & Cohens d \\
\hline \multicolumn{6}{|c|}{ Repeated measures one-way ANOVA: $F(5,347.140)=137.99, p<.001 * *$} \\
\hline \multirow[t]{5}{*}{ Disobedience } & Infidelity & -.342 & .026 & $.001 * *$ & -0.75 \\
\hline & Psychological aggression & -.169 & .019 & $.001 * *$ & -0.45 \\
\hline & Sexual coercion & -.200 & .019 & $.001 * *$ & -0.55 \\
\hline & None & -.010 & .011 & .377 & -0.03 \\
\hline & Physical violence & -.489 & .029 & $.001 * *$ & -0.96 \\
\hline \multirow[t]{4}{*}{ Infidelity } & Psychological aggression & .173 & .022 & $.001 * *$ & 0.33 \\
\hline & Sexual coercion & .142 & .025 & $.001 * *$ & 0.27 \\
\hline & None & .332 & .025 & $.001 * *$ & 0.71 \\
\hline & Physical violence & -.148 & .027 & $.001 * *$ & -0.23 \\
\hline \multirow[t]{3}{*}{ Psychological aggression } & Sexual coercion & -.031 & .020 & .115 & -0.07 \\
\hline & None & .159 & .018 & $.001^{* *}$ & 0.41 \\
\hline & Physical violence & -.320 & .024 & $.001 * *$ & -0.56 \\
\hline \multirow[t]{2}{*}{ Sexual coercion } & None & .190 & .017 & $.001 * *$ & 0.50 \\
\hline & Physical violence & -.289 & .027 & $.001 * *$ & -0.51 \\
\hline None & Physical violence & -.480 & .028 & $.001 * *$ & -0.92 \\
\hline
\end{tabular}

Note: $* * p<.001$ 


\section{d) Is the relationship between provocation type and the aggressor's gender}

influenced by the gender of the participant? A three-way $2 \times 2 \times 6$ mixed ANOVA was conducted to identify whether the interaction between provocation type and aggressor's gender was influenced by the participant's gender. As already identified, a significant interaction was found between the participant's gender and provocation (see Figure 2), and the aggressor's gender and provocation (see Figure 3). The 3-way interaction between aggressor's gender, participant's gender, and provocation was significant $(F(3.80,1938.10)$ $=2.50, \mathrm{p}=.044, \eta \mathrm{p} 2=.005)$. This result shows that male and female respondents have a different pattern of approval when considering provocation context, as well as the gender of the aggressor in the vignette. However, the partial eta squared value of .005 indicates a very small effect size. Therefore, while the 3-way interaction was significant, due to the very small effect size, it is unlikely that the participant's gender is having a meaningful impact on the interaction between provocation type and the aggressor's gender. It is likely approval of IPA is comparable between female (see Figure 4) and male participants (see Figure 5). Thus, it is concluded that female and male participants hold similar views regarding the acceptability of IPA when considering both the provocation context, as well as the aggressor's gender. 


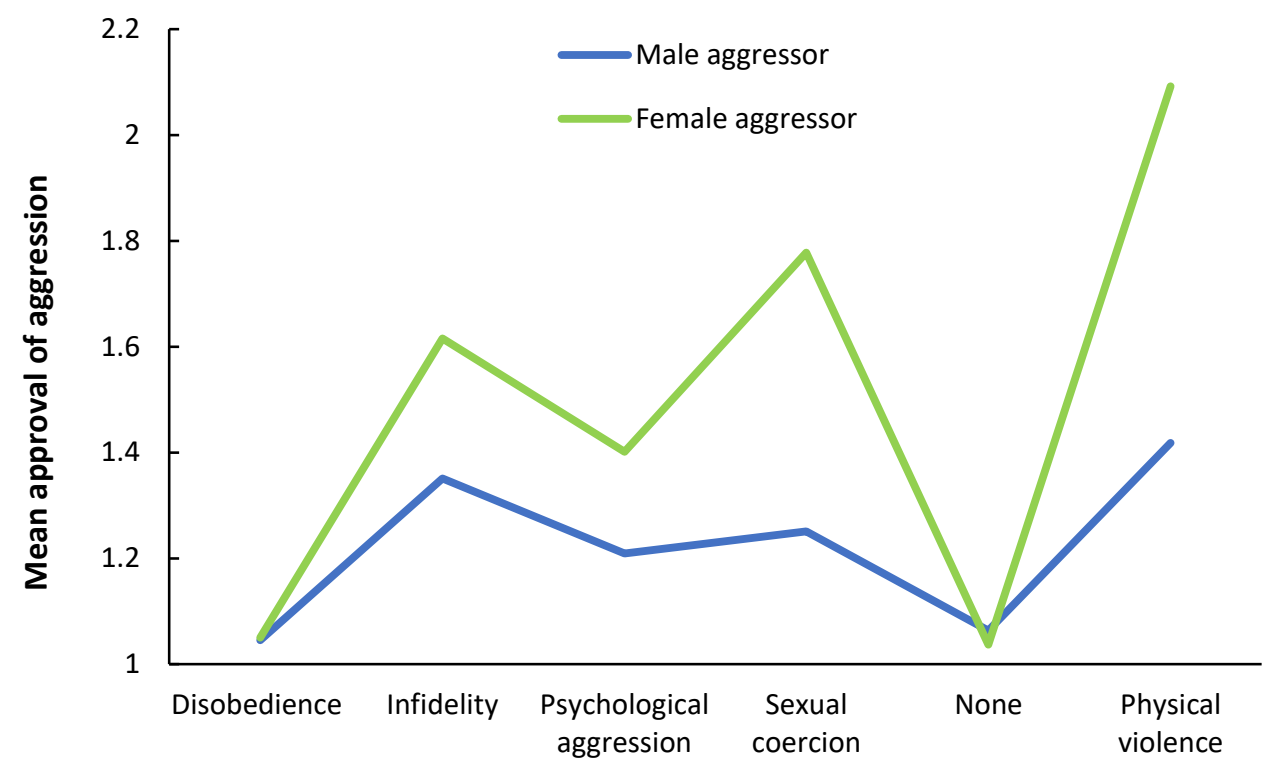

Provocation level

Figure 4. Pictorial representation of female participants' approval of IPA used by either a male or female in a heterosexual relationship; in the context of different types of provocation $(n=299)$

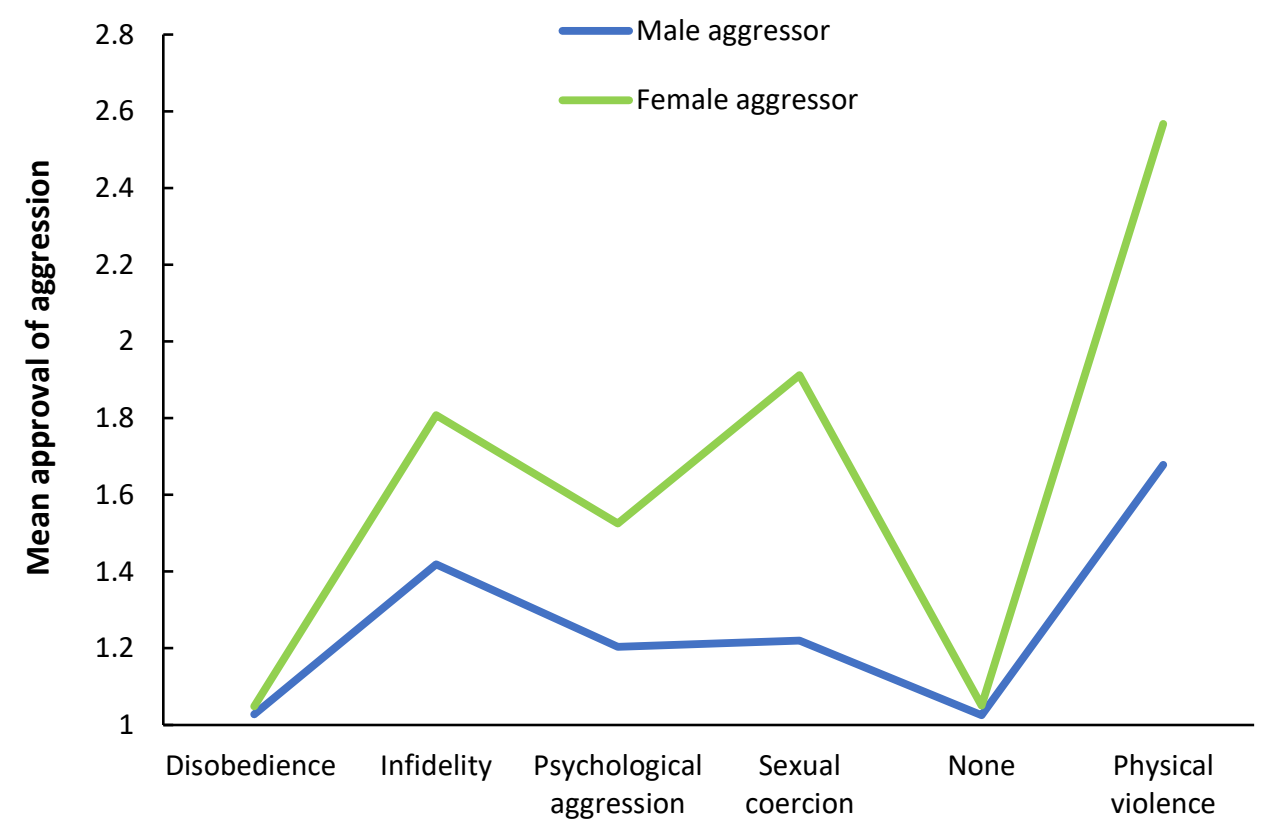

Provocation level

Figure 5. Pictorial representation of male participants' approval of IPA used by either a male or female in a heterosexual relationship; in the context of different types of provocation $(n=$ 216) 
Notably, the results of the 3-way ANOVA also revealed additional findings that were not part of the initial research question but are interpretable. As depicted in Figure 6 below, a significant interaction was found between aggressor's gender and participant's gender $(F(1$, $\left.513)=18.300, p<.001, \eta_{\mathrm{p}}{ }^{2}=.034\right)$. The effect size of .034 indicates a small effect size. These findings indicate that approval of aggression directed at men and women is influenced by the gender of the participant.

Post hoc repeated measures one-way ANOVAs were run separately for male and female participants to identify whether approval of aggression differed when the aggressor in the vignette was a male or a female. Results showed that both male and female participants approved of female aggression significantly more than male aggression; $(F(1,215)=318.600$, $\left.p<.001, \eta_{\mathrm{p}}{ }^{2}=.60\right)$ and $\left(F(1,298)=254.002, p<.001, \eta_{\mathrm{p}}{ }^{2}=.50\right)$ respectively. Additionally, post hoc one-way between subjects ANOVAs revealed that when the aggressor in the vignette was male, approval did not significantly differ by participant's gender $(F(1,513)=1.70, p=$ $\left..200, \eta_{\mathrm{p}}^{2}=.003\right)$, with males $(M=1.30, S D=0.30)$ and females $(M=1.22, S D=.40)$ both holding low approval of male aggression. However, when the aggressor in the vignette was female, results showed that males $(M=1.70, S D=0.40)$ were significantly more approving of aggression than females $\left(M=1.50, S D=0.50 ;\left(F(1,513)=16.700, p<.001, \eta_{\mathrm{p}}{ }^{2}=.031\right)\right.$. Therefore, whilst participants in general approved of female aggression more than male aggression, this was especially true for male participants. 


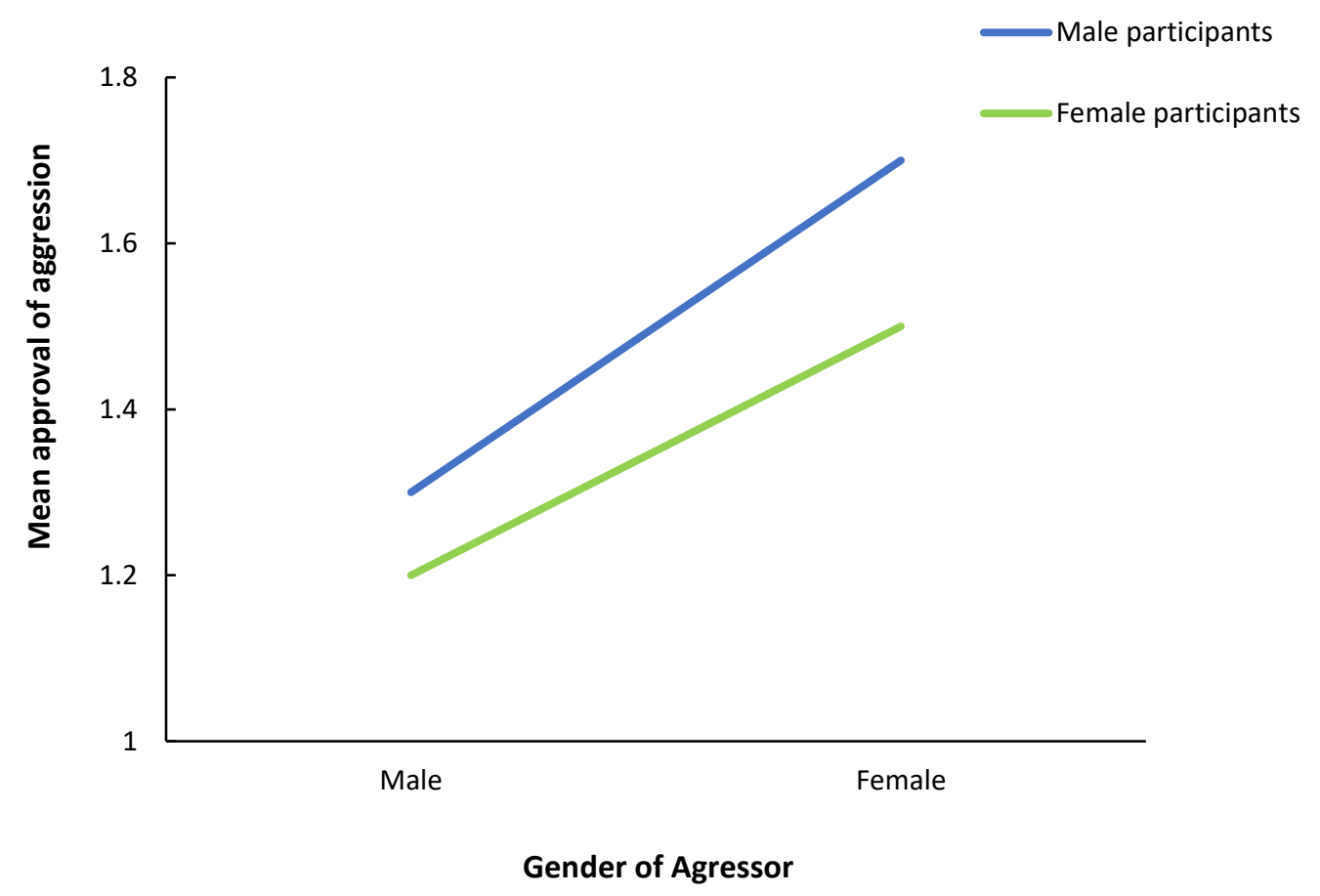

Figure 6. Pictorial representation of male and female participants' approval of IPA used by either a male or female aggressor $(N=515)$

Research Question Three: Do students who self-report perpetrating IPA in the previous 12 months differ in their approval ratings of third parties' IPA compared to students who do not self-report perpetrating IPA?

To identify how approval differed between participants that used IPA in the 12 months prior to completing the survey (aggressive) and those that did not (non-aggressive) a three-way 2x2x2 mixed ANOVA was conducted. Participant's gender (two levels: male and female) and IPA status (two levels: aggressive and non-aggressive) were the between subjects factors, while aggressor's gender (two levels: male and female) was the within subjects factor.

Results showed a main effect of aggression status $\left(F(1,511)=32.664, p<.001, \eta_{\mathrm{p}}{ }^{2}=\right.$ $.060)$, with aggressive participants holding significantly higher approval $(M=1.52, S D=$ $0.44)$ than non-aggressive participants $(M=1.34, S D=0.30)$. These findings indicate that 
previous use of IPA may be related to participants' approval of partner violence in the vignettes. As observed previously in the analysis of research question two (see Figure 6), results also showed an interaction between aggressor's gender and participants' gender $(F(1$, $\left.511)=13.043, p<.001, \eta_{\mathrm{p}}^{2}=.025\right)$. However, no interaction was found between IPA status and aggressor's gender $\left(F(1,511)=0.40, p=.60, \eta_{\mathrm{p}}^{2}=.001\right)$, or IPA status and participant's gender $\left(F(1,511)=0.02, p=.893, \eta_{\mathrm{p}}^{2}=.000\right)$. Additionally, no three-way interaction was found between IPA status, participant's gender, and aggressor's gender $(F(1,511)=3.30, p$ $\left.=.072, \eta_{\mathrm{p}}{ }^{2}=.006\right)$. Therefore, aggressive participants held a higher mean approval of IPA regardless of whether the participant was a male or female and regardless of whether the aggressor in the vignette was a male or female.

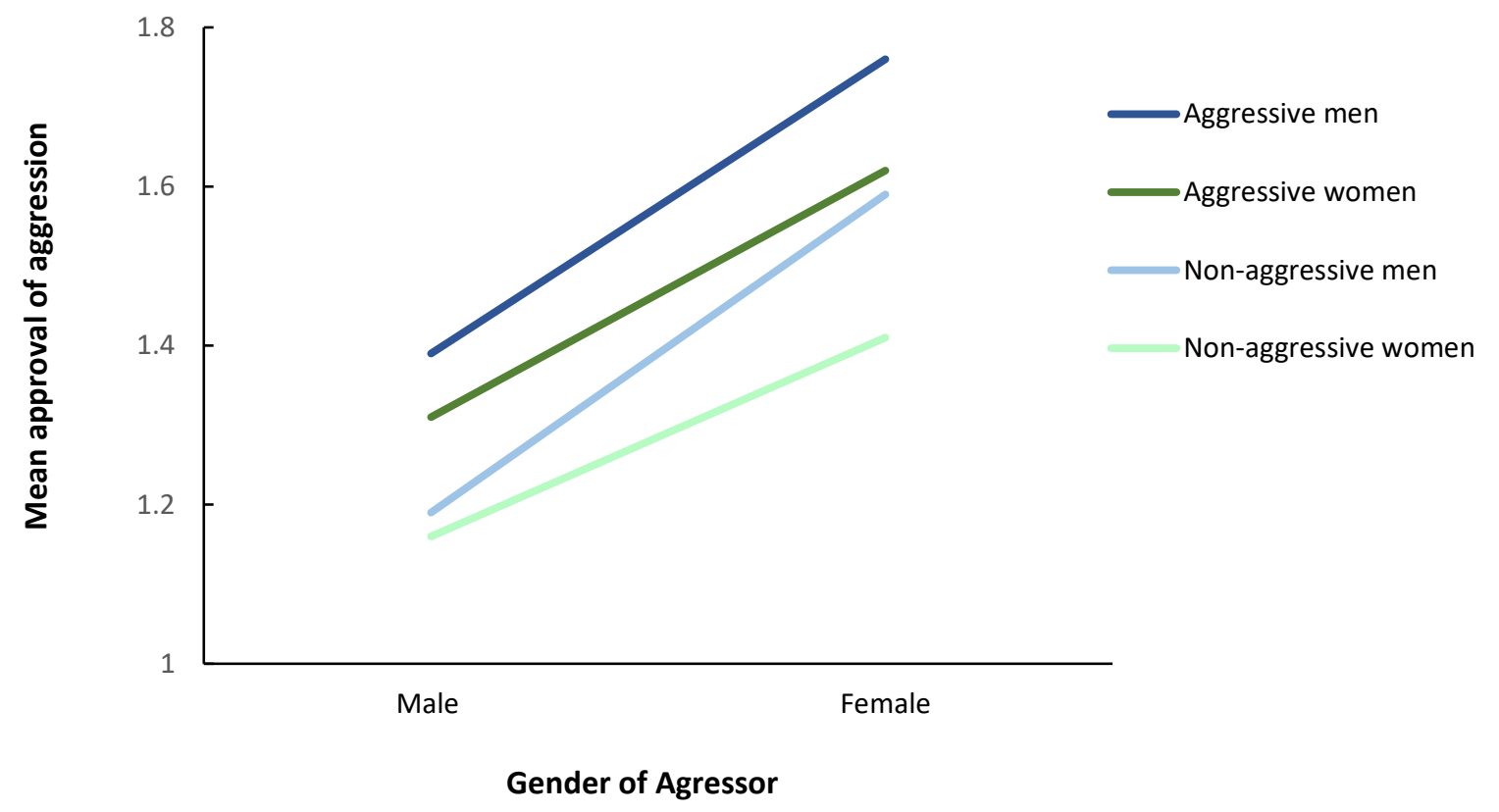

Figure 7. Aggressive $(n=186)$ and non-aggressive $(n=329)$ men's and women's mean approval of IPA used by a male or female aggressor depicted in the BaRAS vignettes $(N=$ 515) 


\section{Discussion}

This study aimed to explore the relationship between participants' approval rates of IPA carried out by a third party and their experiences of IPA in a sample of male and female, heterosexual, New Zealand university students. More specifically, three research questions were explored and will be summarised and a discussed in turn. Following this, implications for research and applications for practice will be discussed.

\section{Summary of Findings}

Research Question One. The first research question sought to investigate the rates and nature of different forms of IPA used by male and female university students. The prevalence of conflict tactics and controlling behaviours found in the present study are within the range reported in previous research (Douglas \& Straus, 2006; Hines \& Saudino, 2003; Russell \& Oswald, 2001; Straus, 2004). For example, this study found severe physical assault was perpetrated by 5.6 percent of men and 10.7 percent of women. Such findings are consistent with Straus (2004) who measured the rates of severe physical assault in 31 universities internationally and found perpetration rates ranging from 1.5 to 21.2 percent for men and 3.0 to 25.8 percent for women. As with previous research, bivariate analysis in the present study found that the majority of conflict and controlling tactics were experienced and perpetrated at approximately equal rates by men and women. While infrequent, some significant differences were found between men's and women's experiences. Women reported using more threatening behaviours and severe physical aggression than men, while men reported using and experiencing more minor physical aggression than women. Men also reported using more minor sexual coercion than women. This finding is in accordance with a study of 16,000 university students from 22 university sites internationally which found men reported using more sexually coercive behaviour than women in 20 of the 22 university sites, with rates 
ranging from 9.3 to 62.2 percent for men and 5.9 to 28.9 for women (Chan, Straus, Brownridge, Tiwari, \& Leung, 2008). Although the statistical differences found in the present study were statistically significant, the effect sizes were small. Therefore, the overall pattern of results suggest that men and women engage in controlling and conflict tactics at comparable rates. Such findings are consistent with previous research that collect reports from men and women (e.g., Graham-Kevan \& Archer, 2009; Straus \& Gelles, 1986; Straus et al., 1990). Accordingly, the current study adds to the body of literature challenging the gendered view that the vast majority of IPA is perpetrated by men (R. P. Dobash \& Dobash, 2004; Yllo, 1983). Instead the present findings suggest that a gender inclusive approach, which acknowledges both men's and women's experiences of partner violence, may offer a better approach to understanding IPA.

The prevalence of injury found in the present study ranged from 0 - 4 percent for men and women, which is within the range of 1.5 to 20 percent reported by Straus (2004) across 31 universities internationally. Furthermore, the present study found no statistical difference between the percentage of males and females who inflicted physical injury, both minor or severe, upon their partners. These findings are also supported by previous research (e.g., Busch \& Rosenberg, 2004; Henning \& Feder, 2004; Melton \& Belknap, 2003) that suggests female violence is just as likely to cause harm as male violence (Whitaker, Haileyesus, Swahn, \& Saltzman, 2007). It is possible that these findings were due to low rates of severe and minor injuries in the present sample, which may have resulted in statistical power being too low to detect differences. However, taken together with research showing women are more likely to use a weapon against their partners (Busch \& Rosenberg, 2004; Melton \& Belknap, 2003), it is also possible that women's aggression is just as consequential as men's. Indeed, even when research has found gender differences in injury rates (e.g., Archer, 2000; Straus, 2004), these are not hugely dissimilar. Archer's (2000) meta-analysis of over 64,000 participants indicated 
that, of those victims requiring hospital treatment for injury, 38 percent were men. Such findings highlight that a gender inclusive understanding of IPA is required.

Finally, present findings found little difference between use and experience of IPA for both men and women, which highlights the reciprocal use of violence in relationships. These findings are in line with previous research by Whitaker et al. (2007) who found that half of the violent relationships in their study were characterised by reciprocal violence. This is especially concerning considering that Whitaker et al. (2007) also found reciprocal violence is more likely to result in injury than non-reciprocal violence, regardless of whether the victim is a male or female. Taken together, these findings highlight that it is important to explore the experiences of both men and women when studying IPA, in line with the gender inclusive approach.

Research Question Two. Research question two explored the extent that students approved of aggression by third party heterosexual couples in different provocation contexts. In accordance with previous literature, the present study showed that the type of provocation had a significant impact on participants' approval of IPA, with the majority of effect sizes indicating a large or medium effect (e.g., Choi \& Edleson, 1996; Forbes et al., 2005). When disobedience or no provocation preceded IPA, low levels of approval were found in the present study. However, when physical violence, infidelity, and sexual coercion preceded IPA, approval was significantly higher and had large effect sizes. In accordance with Cauffman (2000), these results indicate that participants were disapproving of unprovoked aggression or aggression used when the other partner was disobedient. These findings are consistent with Fanslow, Robinson, Crengle and Perese's (2010) study of 2,674 New Zealand women that found almost all participants were disapproving of male violence used in response to disobedience or not doing household tasks adequately. The present study added to Fanslow et al's. (2010) study as it explored both men's and women's beliefs and therefore can give a more 
comprehensive picture of how approval of partner violence differs in certain circumstances. Additionally, disapproval of IPA used by men in the context of disobedience indicates that male and female students may not endorse the patriarchal expectation that women obey their male partners. Therefore, these results reinforce the idea that patriarchy does not appear to be the prevailing norm in this sample and challenges the gendered perspective.

The current study also found that men and women were both more likely to approve of IPA used in response to physical aggression compared to other forms of provocation, highlighting the participants' approval of reciprocal aggression in relationships. Additionally, when examining the gender differences in approval, results showed that men approved of physical retaliation to physical aggression significantly more than women. Therefore, in line with the results from research question one, that showed participants engage in reciprocal aggression, it appears that people most readily approve of reciprocal aggression and that this approval is especially prominent in men.

Consistent with previous findings (e.g., Sorenson \& Taylor, 2005; Werner \& Nixon, 2005), results also showed that the aggressor's gender in the vignette significantly influenced approval rates where there was credible provocation (i.e., sexual coercion, infidelity, or physical assault). Students held significantly higher approval, with large effect sizes, of femaleto-male IPA than male-to-female IPA. Such findings indicate that the aggressor's gender and the context in which the aggression occurs are important factors that together influence male and female students' approval of IPA. Notably, the three-way interaction between participants' gender and provocation, and the aggressor's gender, had a very small effect size. This indicated that male and female participants held a similar pattern of approval when considering both the type of provocation and the aggressor's gender. It is therefore important to consider the interaction of these factors when exploring gender differences in approval of IPA. 
Participants' higher approval of female-to-male IPA compared to male-to-female IPA suggests that, among students in Western societies, beliefs about appropriate male behaviour reflects protection of women (chivalry), rather than approval of violence against women (patriarchy), as gendered theory suggests. Considering research often assumes that individual beliefs are likely indicative of wider social norms, it is possible that the chivalrous beliefs found in the current sample may also exist at a societal level (Felson, 2000; Ireland, 2009). Indeed, previous research has found similar findings in representative community samples (e.g., Felson \& Feld, 2009). However, given individual beliefs can differ from the prevailing norm conclusions should be made tentatively (Ireland, 2009). Nevertheless, students in the current study clearly viewed male aggression as less acceptable than female aggression, which questions the notion that patriarchy, or a system that is more approving of violence against women, is the sole driver of IPA.

When the effect of participants' gender was explored further, results showed that male students held higher approval of female-to-male IPA compared to females. However, men and women did not differ in their approval of male-to-female IPA. Therefore, while students in general approved of female-to-male IPA more than male-to-female IPA, male students were especially approving of female violence toward their own gender. Such findings indicate that chivalrous beliefs were the most pronounced in men. Considering chivalrous norms largely highlight men's responsibility to protect women, it is perhaps not surprising that male students appear to have internalised this belief more than female students. Additionally, men's approval of female aggression might explain why male victims of female aggression are less likely to seek help or view their experiences as abusive (Tsui, Cheung, \& Leung, 2010). These findings are supported in part by Spencer, Morgan, Bridges, Wash-Busk, and Stith's (2017) recent study of university students' approval of IPA, which also found men approved of male-to-female IPA more than female students. This difference could be explained by variations in 
methodology between the studies. Spencer et al. (2017) measured approval of IPA with an adapted version of the "Wife Beating Is Justified" subscale from the Inventory of Beliefs about Wife Beating Scale (Saunders, Lynch, Grayson, \& Linz, 1987). This measure asks questions regarding approval of partner violence in the context of marriage (e.g., "sometimes it's okay for a man to beat his wife" or "sometimes it's okay for a woman to beat her husband"). The present study measured approval using the Beliefs about Relationship Aggression Scale, a measure which has been specifically designed to provide a neutral relationship context suitable to a student population. It is likely the BaRAS is more relevant to a modern dating sample and likely has more ecological validity than the "Wife Beating Is Justified" subscale that focuses on marital relationships. However, replication is needed to explore this further.

While the present findings challenge the gendered theory of IPA, this study does not seek to refute the persuasiveness of sexism within society. Instead it is proposed that sexism manifests within IPA differently than gendered theories suggest. For instance, greater approval of female aggression could be explained by the participants' use of benevolent gendered stereotypes (i.e., women as weak and fragile, and men as strong and threatening) to inform their judgements about the acceptability of male and female aggression (Seelau \& Seelau, 2005). As a result, female aggression may be viewed as trivial, while male aggression may be viewed as more serious and having greater consequences for women. Such sexist inferences could lead to identical aggressive acts, such as slapping a partner because they were unfaithful, being perceived as more acceptable when perpetrated by a female opposed to a male. Indeed, previous research has shown that students judge men as more capable of injuring a victim than females (Seelau \& Seelau, 2005). Given that traditional gender stereotypes are thought to be perpetuated by patriarchal systems within society, patriarchy likely plays a role in explaining the trivialisation of female violence and approval of female aggression. However, further research would be needed to determine the accuracy of this hypothesis. Additionally, although 
sexism may play a role in IPA it is likely not the sole cause, as shown by multifactor models of IPA (Dutton \& Corvo, 2006; Stith, Smith, et al., 2004).

Research Question Three. Research question three investigated whether students who self-reported perpetrating IPA in the previous 12 months differ in their approval ratings of a third party's IPA compared to students who did not self-report perpetrating IPA. It was found that, regardless of the participants' gender or the aggressors' gender in the vignette, participants who had assaulted their partners in the last 12 months approved of IPA significantly more than participants who had not physically assaulted their partners. This finding is supported by previous research (e.g., Archer \& Graham-Kevan, 2003; Dibble \& Straus, 1980; Stith, Smith, et al., 2004). Given that approval of partner aggression was related to the use of IPA for both men and women, these findings support the notion that the approval of IPA in general offers a better explanation for male and female perpetrated IPA than patriarchal beliefs that promote men's violence against women.

It is possible that higher tolerance of IPA increases the chance of engaging in relationship aggression. Indeed, this is consistent with Huesmann's (1988) information processing model of aggression which highlights that, for aggression to occur, the aggressor is likely to approve of using aggression towards the target (i.e. an intimate partner). However, causation cannot be inferred until it is determined how these beliefs developed. Aggressive participants may have developed approval of IPA following their experiences of IPA (Bem, 1972). For instance, an individual might believe hitting their partner is unacceptable, then find themselves in a position where they have hit their partner. In this situation, cognitive dissonance may occur whereby an individual's beliefs (hitting others is unacceptable) and behaviours (hitting their partner) are inconsistent. This produces discomfort which can be reduced by changing either their beliefs or behaviours to match (Bem, 1972). Consequently, it 
is possible that participants developed an approval of IPA following their perpetration of IPA. However, such inferences are beyond the scope of the results of this thesis.

It is interesting to note that students held low approval of IPA in general (i.e., approval ranged from 1.04 to 1.9 on a scale from $1=$ not at all to $5=$ definitely approve). This is consistent with Cauffman et al's. (2000) study of university students, which found approval rates ranging from 1.07 to 2.74 on a scale from 1 (totally unacceptable) to 4 (totally acceptable). While small increases in approval could impact on the likelihood of perpetrating IPA (Spencer et al., 2017), low approval may also suggest multiple factors help to explain the aetiology of IPA. Therefore, a multifactorial explanation of IPA, that incorporates risk factors from various systems (Bell \& Naugle, 2008; Dutton, 2006), may be a more suitable explanation of IPA aetiology than single factor models, such as gendered theory.

\section{Applications to Practice}

The present study found a relationship between men's and women's approval of partner violence and their use of IPA. This highlights that IPA perpetrators may benefit from receiving treatment that targets their approval of aggression towards their partners, regardless of whether they are men or women. However, present treatment programmes commonly target male aggression and are based on the Duluth Model, which encompasses the idea that patriarchal beliefs need to be challenged to make change (Dutton \& Corvo, 2006). This is despite a lack of empirical support for the theory (Dixon \& Graham-Kevan, 2011; Dutton \& Corvo, 2006). Indeed, several experimental outcome studies have shown effect sizes of zero for interventions based on this model, indicating a lack of effectiveness (Davis \& Taylor, 1999; Feder \& Forde, 1999). However, it appears even interventions that take a cognitive behavioural therapy (CBT) approach, that use skills training, examine the pros and cons of violence, and promote awareness of alternatives to violence, have little impact on reducing recidivism. A metaanalysis comparing the effectiveness of treatments that use the Duluth Model to those 
employing a CBT approach showed that both interventions had a minimal effect on reducing recidivism and did not demonstrate the superiority of one intervention over the other (Babcock, Green, \& Robie, 2004). Babcock et al. (2004) acknowledged that many interventions tend to mix theoretical perspective, resulting in a hybrid of the two approaches. Considering this, it is not surprising that results showed no significant difference between treatments (Babcock et al., 2004). Additionally, most treatments focused primarily on men's violence and attitudes and do not address the gender symmetry in IPA perpetration, nor do they acknowledge the relational aspects of IPA. Such shortcomings might help to explain the apparent ineffectiveness of current treatment programmes and indicates that a new approach to IPA interventions is needed.

Together with the present findings, this evidence indicate that intervention programmes need to move beyond a gendered perspective and take a more nuanced approach to partner violence treatment. Intervention programmes that target both men's and women's approval of their own use of partner violence and their approval of a person's aggression toward them may have a greater impact on reducing the relatively high rates of partner violence, both in New Zealand and internationally. Additionally, men's and women's strong approval of retaliation to physical aggression may explain the high rates of reciprocal aggression in this sample. Therefore, treatment also needs to consider the high rates of reciprocity in IPA and how to introduce alternative strategies in response to physical attackers, in addition to selfdefence.

The point that treatment programmes may need to address the individual's approval of using IPA against their partner in conjunction with their approval of their partner's use of IPA against them is an important one considering that research has found 49.7 percent of young adults (aged 18 to 28 years) reported being involved in reciprocally violent relationships that were more likely to result in serious injuries than unidirectional violence (Whitaker et al., 2007). Such findings suggest that treatment programmes that focus solely on one partner's 
beliefs and behaviours, but ignores the relational aspects of partner violence, may not adequately address the issue. It is also possible that if an individual's approval of aggression is targeted and reduced, but they continue to tolerate aggression being used against them, they may stay in an abusive relationship and become involved in this cycle of violence again. Indeed, men who had completed the 'Stopping Violence' group, an IPA treatment intervention group in New Zealand, expressed the need for the contextual elements of their relationship (e.g., the other partner's harassment) to be considered during treatment (Mitchell \& Chapman, 2014).

The present study also provides some insight into how individuals involved in IPA might be treated by people they turn to for help, such as family, friends, or professionals. Results showed that people are more approving of IPA under certain circumstances, such as when the victim is unfaithful, sexually coercive, or uses physical violence first. This is concerning because, if individuals witness, or are told about IPA occurring in these contexts, they might be less likely to offer help or report the issue to the authorities (Garcia-Moreno, Jansen, Ellsberg, Heise, \& Watts, 2006). Further, despite research showing that men and women experience IPA at similar rates (e.g., Graham-Kevan \& Archer, 2009; Straus \& Gelles, 1986), individuals were more approving of male victimisation, perhaps because female violence is seen as trivial. Unfortunately, such approval may deter men from reporting their victimisation as they may think, perhaps rightly so, that others will view their abuse as trivial. Additionally, research has shown that professionals, such as police and psychologist, may hold similar beliefs to the students in this study, who generally approve of female aggression more than male aggression. Felson and Pare (2007) showed that female offenders of IPA are treated more leniently by police than male offenders, while Follingstad, Bradley, and Laughlin (1999) found practicing psychologists described male violence as more pathological and dangerous than women's. This is alarming when considering the influence such professionals have on 
people's lives, for instance whether an individual acquires a police record. In light of these concerns, an education effort is required to challenge both the general population's and professionals approval of female aggression and aggression that is thought to have been provoked.

The present findings also suggest education efforts should specifically target men's approval of female aggression. This study revealed that men themselves are the most approving of male victimisation (or female aggression). This could have two significant consequences; 1 ) heterosexual men who experience IPA may not see this as abuse, seek help, or leave the relationship; 2) if men disclose their abuse to male friends or family members, it may not be considered a serious issue, which may further perpetuate the individual's belief that their abuse is trivial. In support of this notion, research has shown that a large barrier to male victims seeking support is stigmatization, embarrassment, and denial (Tsui et al., 2010). To lessen this problem, education campaigns in universities, and the wider communities, should endeavour to reduce the stigma around male victimisation and inform people about the consequences of both male and female violence.

Taken together, it appears IPA education campaigns may benefit from using a gender inclusive approach that acknowledges IPA is experienced by both men and women. Further, the message that violence is unacceptable in all circumstances, regardless of whether the aggressor was provoked or was a female, should be disseminated. Current programmes in New Zealand go some of the way to achieving this. For example, the "It's not OK" Campaign, is centred on the idea that is it not okay to hit or verbally abuse your partner or children (Point Research Ltd., 2010). While, the message that "it's not okay" does stress that violence is unacceptable in a gender inclusive way, some aspects of the campaign took a more gendered approach. An example of this is that only men were depicted as perpetrators and only their stories of perpetrating IPA were used (Point Research Ltd., 2010). Dixon and Grahan-Kevan 
(2011) highlighted that this may be problematic because if primary prevention campaigns only apply to a subset of people (i.e. men who use violence against women) and do not represent what the majority of the general population experience, the message will likely not be internalised as something that applies to them. Nevertheless, this campaign did challenge the public perception of how acceptable IPA is and likely increased reporting of IPA (Point Research Ltd., 2010). Given the present study found high rates of IPA in a student population, it appears primary prevention campaigns targeting this population are needed. Clark University in the United States has recognised the high rates of IPA in student populations and is leading the way with the Clark Anti-Violence Education Program (Clark University, 2017). The programme takes a gender inclusive approach to IPA prevention and is completed by all incoming students. While New Zealand universities currently do not address the high rates of IPA in students, in secondary schools an effort has recently been made to combat this issue. With the aim to reduce sexual and dating violence among youth, the 'Mates and Dates' primary prevention programme teaches young people skills to develop and maintain healthy relationships. An evaluation of the programme showed that, following the completion of five 50 minute sessions, students held more pro-social attitudes regarding relationships and reported that they were more confident in recognising risky situations and seeking help. Considering the current study found attitudes approving of IPA were related to perpetration of IPA, positive changes in such attitudes following completion of the 'Mates and Dates' programme suggests that this may lead to reductions in youth IPA. Further, given the high rates of IPA found in university samples, perhaps implementing similar developmentally appropriate programmes in New Zealand universities would be valuable.

\section{Limitations and Future Research}

It is important to acknowledge limitations of the current study. Firstly, a student sample was utilised and while previous research has shown this group engages in relatively high levels 
of IPA compared to the general population and is therefore important to research (Ministry of Justice, 2015), the results cannot be generalised to the wider population. Future research could use a representative community sample to explore the relationship between approval of IPA and aggression. Additionally, this study used an aggregate measure of individual beliefs about the acceptability of IPA, while individual normative beliefs likely relate to wider social norms, some scholars argue that to truly understand social norms, data needs to be collected at a social level through analysis of media or the structural characteristics of the social system (Lapinski \& Rimal, 2005). Therefore, future research could build on the current findings by measuring wider social norms in addition to individual normative beliefs as described by Huesmann (1997). The relationship between the two levels of beliefs could then be determined.

As previously discussed, due to the design of the present study, causation cannot be inferred between approval and perpetration of IPA. It cannot be determined whether approval of IPA was held prior to, or following, IPA perpetration. Longitudinal research would add to the present findings as changes in approval over time, and how this relates to experiences of IPA, could be measured. Further, the current study did not examine whether the controlling and conflict tactics experienced by participants were used in response to their partner's use of these tactics. In the future, research should endeavour to gain information about the context in which tactics were used through survey questions or qualitative data collection.

It should also be acknowledged that the gender of the aggressor and the gender of the victim are confounded in the present study. That is, it is unclear whether participants' disapproval of male aggression is driving the current findings or if disapproval of female victims, who are perceived to be more easily harmed, account for the effects. Alternatively, it may be a combination of these two factors that explain these results. Future research should attempt to disentangle these factors by exploring approval of male-to-male and female-tofemale IPA, as well as male-to-female and female-to-male IPA. 
Despite limitations, the current research is valuable in that it extends upon the literature of IPA in a university student sample, a group that experiences relatively high rates of IPA (Ministry of Justice, 2015). Additionally, the current study utilised a large sample size $(N=$ $515)$ with relatively equal numbers of men $(n=216)$ and women $(n=299)$, increasing the likelihood that the results are representative of this student population. Finally, this research took a gender inclusive approach, asking both men and women about their experiences and approval of IPA. Given research has suggested men and women perpetrate IPA at a similar rate (e.g., Straus \& Gelles, 1986), gaining an understanding of men's and women's experiences of victimisation and perpetration is important.

\section{Conclusion}

This study demonstrates that male and female university students engage in IPA, therefore, aggressive students are not primarily men as gendered theory suggests. Instead, gender symmetry was found where men and women both reported using and experiencing IPA at similar rates. Collectively, the sample held chivalrous beliefs about the approval of IPA, tolerating female aggression significantly more than men's violence to women. Although aggressive students held the same chivalrous approval pattern, they were significantly more approving of male and female aggression compared to non-aggressive students. Whilst longitudinal research is needed to determine causality, these findings suggest approval of IPA is related to the use of IPA for both genders in heterosexual relationships. Therefore, this study proposes that challenging a client's approval of IPA in perpetrator treatment programmes could be beneficial. Additionally, male and female perpetrators of IPA may also benefit from a more nuanced approach to treatment that challenges their approval of using aggression against a partner, as well as their tolerance of aggression being used against them by their partner. This approach accounts for the relational factors of IPA and may help to reduce the high rates of both reciprocal and unidirectional IPA found internationally and in New Zealand. Finally, it is 
important that future research explores the role of chivalrous beliefs regarding approval of IPA found in this study on people's experiences of IPA and help seeking. Not only may this collective belief contribute to reciprocal aggression in relationships, but it may also contribute to the trivialisation of male victimisation resulting in a lack of support and services for men, as well as men's self-recognition of abusive experiences. It is therefore proposed that practice and policy endeavours to adopt a more gender inclusive approach to IPA in the future. 


\section{References}

Abrar, S., Lovenduski, J., \& Margetts, H. (2000). Feminist ideas and domestic violence policy change. Political Studies, 48, 239-262. doi: 10.1111/1467-9248.00258

Akers, R. L., \& Sellers, C. S. (2012). Introduction to Criminological Theory. In Criminological Theories. Introduction, Evaluation, and Application (6th ed., pp. 1-13). New York: Oxford University Press.

Alhabib, S., Nur, U., \& Jones, R. (2010). Domestic violence against women: Systematic review of prevalence studies. Journal of Family Violence, 25(4), 369-382. doi: $10.1007 / \mathrm{s} 10896-009-9298-4$

Allen, C. T., Swan, S. C., \& Raghavan, C. (2009). Gender symmetry, sexism, and intimate partner violence. Journal of Interpersonal Violence, 24(11), 1816-1834. doi: $10.1177 / 0886260508325496$

Archer, J. (2000). Sex differences in aggression between heterosexual partners: A metaanalytic review. Psychological Bulletin, 126(5), 651-680. doi:10.1037/00332909.126.5.651

Archer, J., \& Graham-Kevan, N. (2003). Do beliefs about aggression predict physical aggression to partners? Aggressive Behavior, 29(1), 41-54. doi: 10.1002/ab.10029

Archer, J., \& Haigh, A. (1999). Sex differences in beliefs about aggression: Opponent's sex and the form of aggression. The British Journal of Social Psychology / the British Psychological Society, 38 (1), 71-84. doi:10.1348/014466699164040

Babcock, J. C., Green, C. E., \& Robie, C. (2004). Does batterers' treatment work? A metaanalytic review of domestic violence treatment. Clinical Psychology Review, 23(8), 1023-1053. doi: 10.1016/j.cpr.2002.07.001

Bell, K. M., \& Naugle, A. E. (2008). Intimate partner violence theoretical considerations: Moving towards a contextual framework. Clinical psychology review, 28(7), 1096-1107. 
Bem, D. J. (1972). Self-perception theory. In L. Berkowitz (Eds.), Advances in experimental social psychology (Vol. 6). New York: Academic Press.

Berkowitz, L. (1993). Pain and aggression: Some findings and implications. Motivation and Emotion, 17(3), 277-293. doi: 10.1007/BF00992223

Bettencourt, B., \& Miller, N. (1996). Gender differences in aggression as a function of provocation: A meta-analysis. Psychological Bulletin, 119(3), 422-447. doi: 10.1037/0033-2909.119.3.422

Busch, A. L., \& Rosenberg, M. S. (2004). Comparing women and men arrested for domestic violence: A preliminary report. Journal of Family Violence, 19(1), 49-57. doi: 10.1023/B:JOFV.0000011582.05558.2e

Campbell, J. C. (2002). Health consequences of intimate partner violence. The Lancet, 359 (9314), 1331-1336. doi: 10.1016/S0140-6736(02)08336-8

Cauffman, E., Feldman, S. S., Jensen, L. A., \& Arnett, J. J. (2000). The (un)acceptability of violence against peers and dates. Journal of Adolescent Research, 15(6), 652-673. doi: $10.1177 / 0743558400156003$

Chan, K. L., Straus, M. A., Brownridge, D. A., Tiwari, A., \& Leung, W. C. (2008). Prevalence of dating partner violence and suicidal ideation among male and female university students worldwide. Journal of Midwifery and Women's Health, 53(6), 529_ 537. doi.org/10.1016/j.jmwh.2008.04.016

Choi, A., \& Edleson, J. L. (1996). Social disapproval of wife assaults: A national survey of Singapore. Journal of Comparative Family Studies, 27(1), 73-88.

Clark University. (2017). Clack Anti-Violence Education Program. Retrieved from: http://www2.clarku.edu/offices/cave/

Coker, A. L., Davis, K. E., Arias, I., Desai, S., Sanderson, M., Brandt, H. M., \& Smith, P. H. (2002). Physical and mental health effects of intimate partner violence for men and 
women. American Journal of Preventive Medicine, 23(4), 260-268.

doi.org/10.1016/S0749-3797(02)00514-7

Cross, C. P., Tee, W., \& Campbell, A. (2011). Gender symmetry in intimate aggression: An effect of intimacy or target sex? Aggressive Behavior, 37(3), 268-277. doi.org/10.1002/ab.20388

Davidovic, A., Bell, K., Ferguson, C., Gorski, E., \& Campbell, A. (2011). Impelling and inhibitory forces in aggression: Sex-of-target and relationship effects. Journal of Interpersonal Violence, 26(15), 3098-126. doi: 10.1177/0886260510390953

Davis, R. C., \& Taylor, B. G. (1999). Does batterer treatment reduce violence? Women and Criminal Justice, 10(2), 69-93. doi: 10.1300/J012v10n02_05

Desmarais, S. L., Reeves, K. a., Nicholls, T. L., Telford, R. P., \& Fiebert, M. S. (2012). Prevalence of physical violence in intimate relationships, part 1: Rates of male and female victimization. Partner Abuse, 3(2), 170-198. doi: 10.1891/1946-6560.3.2.170

Dibble, U., \& Straus, M. A. (1980). Some social structure determinants of inconsistency between attitudes and behavior: The case of family violence. Journal of Marriage \& Family, 42(1), 71. doi: 10.2307/351935

Dixon, L., \& Graham-Kevan, N. (2011). Understanding the nature and etiology of intimate partner violence and implications for practice and policy. Clinical Psychology Review, 31(7), 1145-1155. doi: 10.1016/j.cpr.2011.07.001

Dobash, R. E., \& Dobash, R. P. (2001). Domestic violence: Sociological perspectives. In N. Smelser \& P. Baltes (Eds.), International Encyclopedia of the Social \& Behavioral Sciences (pp. 632-635). Amsterdam: Elsevier.

Dobash, R. P., \& Dobash, R. E. (2004). Women's violence to men in intimate relationships: Working on a puzzle. British Journal of Criminology, 44(3), 324-349. doi: 10.1093/crimin/azh026 
Domestic Violence Act (1995). Ministry of Justice. Retrieved from: http://www.legislation.govt.nz/act/public/1995/0086/latest/DLM371926.html

Douglas, E. M., \& Straus, M. A. (2006). Assault and injury of dating partners by university students in 19 countries and its relation to corporal punishment experienced as a child. European Journal of Criminology, 3(3), 293-318. doi: 10.1177/1477370806065584

Dutton, D. G. (2006). Rethinking Domestic Violence. Vancouver: University of British Columbia Press.

Dutton, D. G., \& Corvo, K. (2006). Transforming a flawed policy: A call to revive psychology and science in domestic violence research and practice. Aggression and Violent Behavior, 11(5), 457-483. doi: 10.1016/j.avb.2006.01.007

Esquivel-Santoveña, E. E., \& Dixon, L. (2012). Investigating the true rate of physical intimate partner violence: A review of nationally representative surveys. Aggression and Violent Behavior, 17(3), 208-219. doi: 10.1016/j.avb.2012.02.002

Exner-Cortens, D., Eckenrode, J., \& Rothman, E. (2013). Longitudinal associations between teen dating violence victimization and adverse health outcomes. Pediatrics, 131(1), 718. doi: 10.1542/peds.2012-1029

Fanslow, J., Robinson, E., Crengle, S., \& Perese, L. (2010). Juxtaposing beliefs and reality: prevalence rates of intimate partner violence and attitudes to violence and gender roles reported by New Zealand women. Violence against Women, 16(7), 812-831. doi: $10.1177 / 1077801210373710$

Feder, L., \& Forde, D. R. (1999). A test of the efficacy of court-mandated counseling for convicted misdemeanor domestic violence offenders: Results from the Broward experiment. National Institute of Justice Special Report: Batterer Intervention Programs, Where Do We Go From Here. Washington, D.C.: U. S. Department of Justice. 
Felson, R. B. (1984). Patterns of aggressive social interaction. In: Mummendey A. (eds), Social Psychology of Aggression: From Individual Behavior to Social Interaction (pp 107-126), Berlin, Heidelberg: Springer

Felson, R. B. (2000). Chivalry. In R. Felson (Eds.), Violence and Gender Re-examined. (pp. 67-82). Washington: American Psychological Association.

Felson, R. B., Ackerman, J., \& Yeon, S. J. (2003). The infrequency of family violence. Journal of Marriage and Family, 65(3), 622-634. doi: 10.1111/j.17413737.2003.00622.x

Felson, R. B., \& Feld, S. L. (2009). When a man hits a woman: Moral evaluations and reporting violence to the police. Aggressive Behavior, 35(6), 477-488. doi: 10.1002/ab.20323

Felson, R. B., \& Pare, P. P. (2007). Does the criminal justice system treat domestic violence and sexual assault offenders differently? Justice Quarterly, 24(3), 435-459. doi: $10.1080 / 07418820701485601$

Felson, R. B., Savolainen, J., Hughes, L. A., \& Ellonen, N. (2015). Gender, provocation, and intimate partner aggression. Partner Abuse, 6(2), 186-196. doi: 10.1891/19466560.6.2.180

Field, A. (2013). Discovering Statistics Using SPSS (4 ${ }^{\text {th }}$ ed). Los Angeles: Sage

Follingstad, D. R., Bradley, R. G., Laughlin, J. E., \& Burke, L. (1999). Risk factors and correlates of dating violence: The relevance of examining frequency and severity levels in a college sample. Violence and Victims, 14(4), 365-380. doi.org: $10.1177 / 0886260506287312$

Forbes, G. B., Jobe, R. L., White, K. B., Bloesch, E., \& Adams-Curtis, L. E. (2005). Perceptions of dating violence following a sexualor nonsexual betrayal of trust: Effects of gender, sexism, acceptance of rape myths, and vengeance motivation. Sex Roles, 
52(3), 165-173. doi: 10.1007/s11199-005-1292-6

Garcia-Moreno, C., Jansen, H. A. F. M., Ellsberg, M., Heise, L., \& Watts, C. H. (2006).

Prevalence of intimate partner violence: Findings from the WHO multi-country study on women's health and domestic violence. Lancet, 368(9543), 1260-1269. doi.org:

$10.1016 / \mathrm{S} 0140-6736(06) 69523-8$

Gelles, R. J. (1990). Methodological issues in the study of family violence. In G. Patterson, Depression and aggression in family interaction (pp. 49-74). Hillsdale, New Jersey: Routledge.

Glick, P., \& Fiske, S. T. (1996). The Ambivalent Sexism Inventory: Differentiating hostile and benevolent sexism. Journal of Personality and Social Psychology, 70(3), 491-512. doi: 10.1037/0022-3514.70.3.491

Graham-Kevan, N., \& Archer, J. (2009). Control tactics and partner violence in heterosexual relationships. Evolution and Human Behavior, 30(6), 445-452. doi:

10.1016/j.evolhumbehav.2009.06.007

Hamel, J., \& Nicholls, T. L. (2006). Family Interventions in Domestic Violence : A Handbook of Gender-inclusive Theory and Treatment. New York: Springer Publishing Company.

Hammock, G. S., Richardson, D. S., Lamm, K. B., Taylor, E., \& Verlaque, L. (2017). The Effect of gender of perpetrator and victim on perceptions of psychological and physical intimate partner aggression. Journal of Family Violence, 32(3), 357-365. doi: $10.1007 / \mathrm{s} 10896-016-9850-\mathrm{y}$

Henning, K., \& Feder, L. (2004). A comparison of men and women arrested for domestic violence: Who presents the greater threat? Journal of Family Violence, 19(2), 69-80. doi: 10.1023/B:JOFV.0000019838.01126.7c

Hines, D. A., \& Saudino, K. J. (2003). Gender differences in psychological, physical, and sexual aggression among college students using the revised Conflict Tactics Scales. 
Violence and Victims, 18(2), 197-217. doi: 10.1891/vivi.2003.18.2.197

Huesmann, L. R. (1988). An information processing model for the development of aggression. Aggressive Behavior, 14(1), 13-24. doi:10.1002/10982337(1988)14:1<13::AID-AB2480140104>3.0.CO;2-J

Huesmann, L. R., \& Guerra, N. G. (1997). Children's normative beliefs about aggression and aggressive behavior. Journal of Personality and Social Psychology, 72(2), 408-419. doi: $10.1037 / 0022-3514.72 .2 .408$

Ireland, J. L. (2009). Conducting individualised theory-driven assessments of violent offenders. In J. L. Ireland, A. Ireland, c, \& P. Birch (Eds.), Violent and sexual offenders: Assessment, treatment and management (pp. 68-96). Devon, UK: Willan Publishing.

Kahui, S., \& Snively, S. (2014). Measuring the Economic Costs of Child Abuse and Intimate Partner Violence to New Zealand. Wellington, New Zealand: More Media Enterprises.

Kelmendi, K., \& Baumgartner, F. (2017). Exploring violence socialization and approval of intimate partner violence among university students in kosovo. Journal of Interpersonal Violence, 1-27. doi:10.1177/0886260517692336

Lapinski, M. K., \& Rimal, R. N. (2005). An explication of social norms. Communication Theory, 15(2), 127-147. doi: 10.1093/ct/15.2.127

Laroche, D. (2007). Context and Consequences of Domestic Violence Against Men and Women in Canada in 2004. Violence Against Women. Quebec: Institut la statistique du Quebec.

Magdol, L., Moffitt, T. E., Caspi, a, \& Silva, P. a. (1998). Hitting without a license: Testing explanations for differences in partner abuse between young adult daters and cohabitors. Journal of Marriage and the Family, 60(13615), 41-55. doi: 10.2307/353440

Mandela, L., \& Brundtland, G. H. (2002). World report on violence and health. Geneva, Switzerland: World Health Organization. 
Melton, H., \& Belknap, J. (2003). He hits, she hits: Assessing gender differences and similarities in officially reported intimate partner violence. Criminal Justice and Behavior, 30(3), 328-348. doi:10.1177/0093854803030003004

Ministry of Justice. (2015). Main Findings. Wellington, New Zealnd: Ministry of Justice.

Mitchell, D., \& Chapman, P. (2014). Men at work: Men's views on a stopping violence service. Nelson, New Zealand: SVS - Living Safe.

Point Research Ltd. (2010). An innovative approach to changing social attitudes around family violence in New Zealand: Key ideas, insights and lessons learnt. Wellington, New Zealand: Point Research Ltd.

Reeves, P. M., \& Orpinas, P. (2012). Dating norms and dating violence among ninth graders in northeast georgia: Reports from student surveys and focus groups. Journal of Interpersonal Violence, 27(9), 1677-1698. doi: 10.1177/0886260511430386

Russell, B. L., \& Oswald, D. L. (2001). Strategies and dispositional correlates of sexual coercion perpetrated by women: An exploratory investigation. Sex Roles, 45(1-2), 103115. doi: 10.1023/A:1013016502745

Saunders, D. G., Lynch, A. B., Grayson, M., \& Linz, D. (1987). The inventory of beliefs about wife beating: The construction and initial validation of a measure of beliefs and attitudes. Violence and Victims, 2(1), 39-57.

Seelau, S. M., \& Seelau, E. P. (2005). Gender-role stereotypes and perceptions of heterosexual, gay and lesbian domestic violence. Journal of Family Violence, 20(6), 363-371. doi: 10.1007/s10896-005-7798-4

Simons, R. L., Lin, K., \& Gordon, L. C. (1998). Socialization in the family of origin and male dating violence: A prospective study. Journal of Marriage and the Family, 60(2), 467-478. doi.org: $10.2307 / 353862$

Sorenson, S. B., \& Taylor, C. A. (2005). Female aggression toward male intimate partners: 
An examination of social norms in a community-based sample. Psychology of Women Quarterly, 29(1), 78-96. doi: 10.1111/j.1471-6402.200

Spencer, C. M., Morgan, P., Bridges, J., Washburn-Busk, M., \& Stith, S. M. (2017). The relationship between approval of violence and intimate partner violence in college students. Journal of Interpersonal Violence, 1-20. doi: 10.1177/0886260517731315

Stewart, L. A., Flight, J., \& Slavin-Stewart, C. (2013). Applying effective corrections principles (RNR) to partner abuse interventions. Partner Abuse, 4(4), 494-534. doi: $10.1891 / 1946-6560.4 .4 .494$

Stith, S. M., Rosen, K. H., McCollum, E. E., \& Thomsen, C. J. (2004). Treating intimate partner violence within intact couple relationships: Outcomes of multi-couple versus individual couple therapy. Journal of Marital and Family Therapy, 30(3), 305-318. doi: 10.1111/j.1752-0606.2004.tb01242.x

Stith, S. M., Smith, D. B., Penn, C. E., Ward, D. B., \& Tritt, D. (2004). Intimate partner physical abuse perpetration and victimization risk factors: A meta-analytic review. Aggression and Violent Behavior, 10(1), 65-98. doi: 10.1016/j.avb.2003.09.001

Straus, M. A. (2004). Prevalence of violence against dating partners by male and female university students worldwide. Violence Against Women, 10(7), 790-811. doi: $10.1177 / 1077801204265552$

Straus, M. A., \& Gelles, R. J. (1986). Societal change and change in family violence from 1975 to 1985 as revealed by two national surveys. Journal of Marriage and the Family, 48(3), 465-479. doi: 10.2307/352033

Straus, M. A., Gelles, R. J., \& Smith, C. (1990). Physical violence in American families: Risk factors and adaptations to violence in 8,145 families. New Brunswick, NJ: Transaction Publishers.

Sugarman, D. B., \& Frankel, S. L. (1996). Patriarchal ideology and wife-assault: A meta- 
analytic review. Journal of Family Violence, 11(1), 13-40. doi: 10.1007/BF02333338

Tabachnick, B. G., Fidell, L. S., \& Osterlind, S. J. (2001). Using multivariate statistics (6th ed.). Boston: Pearson.

Taylor, S. P., \& Epstein, S. (1967). Aggression as a function of the interaction of the sex of the aggressor and the sex of the victim. Journal of Personality, 35(3), 474-486. doi: 10.1111/j.1467-6494.1967.tb01441.x

Tjaden, P., \& Thoennes, N. (2000). Prevalence, incidence, and consequences of violence against women: Findings from the national violence against women survey. Violence Against Women, 6(2), 142-161. doi: 10.1177/10778010022181769

Tsui, V., Cheung, M., \& Leung, P. (2010). Help-seeking among male victims of partner abuse: Men's hard times. Journal of Community Psychology, 38(6), 769-780. doi: 10.1002/jcop.20394

Werner, N. E., \& Nixon, C. L. (2005). Normative beliefs and relational aggression: An investigation of the cognitive bases of adolescent aggressive behavior. Journal of Youth and Adolescence, 34(3), 229-243. doi: 10.1007/s10964-005-4306-3

Whitaker, D. J., Haileyesus, T., Swahn, M., \& Saltzman, L. S. (2007). Differences in frequency of violence and reported injury between relationships with reciprocal and nonreciprocal intimate partner violence. American Journal of Public Health, 97(5), 941947. doi: 10.2105/AJPH.2005.079020

Yllo, K. (1983). Sexual equality and violence against wives in American States. Journal of Comparative Family Studies, 14(1), 67-86. Retrieved from: http://www.jstor.org/stable/41601328

Zimring, F. E., Mukherjee, S. K., \& Winkle, B. V. (1983). Intimate violence: A study of intersexual homicide in Chicago. The University of Chicago Law Review, 50(2), 910930. doi: $10.2307 / 1599514$ 


\title{
Appendices
}

\section{Appendix A: Information and consent sheet}

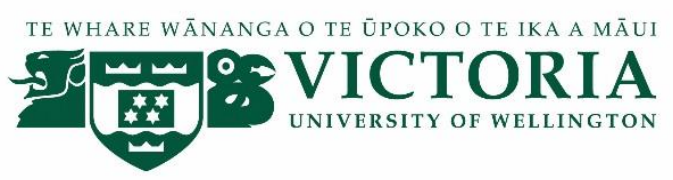

EXPERIENCES AND PERCEPTIONS OF AGGRESSION IN INTIMATE RELATIONSHIPS

\author{
INFORMATION AND CONSENT SHEET: Project \# 22554 \\ Louise Dixon, Reader $\quad$ Saara Cavanagh \\ Louise.Dixon@vuw.ac.nz_cavanasaar@myvuw.ac.nz
}

Thank you for your interest in this project. Please read this information before deciding whether or not to take part. If you decide to participate, thank you. If you decide not to take part, thank you for considering my request.

\section{Who are we?}

Louise Dixon is a Reader/Associate Professor in Forensic Psychology at Victoria University of Wellington. She is the lead researcher on this project. Saara Cavanagh is studying her honours year in Psychology at Victoria University of Wellington and is conducting this project under Louise Dixon's supervision for part completion of her degree. 


\section{What is the aim of the project?}

This study investigates how people manage conflict and view the use of aggression between intimate or dating partners. To be eligible to take part in this study, you must be at least 18 years old and have been in a dating/intimate relationship that has lasted for at least one month at some point in your adolescent/adult life.

This research has been approved by the School of Psychology Human Ethics Committee under delegated authority of Victoria University of Wellington's Human Ethics Committee [project\# 2254].

\section{What is involved if $I$ agree to participate?}

If you agree to take part, you will complete the questionnaire online. You will be asked to answer questions about how you solve conflict and whether you have experienced aggression or control in your past and current relationships. In addition, you will be asked to read short scenarios which describe partners aggressing against each other and to comment on which behaviours you think are acceptable. 
It will take you approximately 45-60 minutes to complete. It is important that any information received is accurate. I therefore ask you to complete the questionnaire in a private, quiet space, consider each question carefully and answer each question honestly.

There are six sections to the questionnaire. The first asks for general demographic information. The second asks you to consider ways in which you may have solved conflict in your relationships. For example, questions will ask if you have ever done any of the following to a partner or if a partner has done this to you: showed them care; showed respect; punched or kicked; used a knife or gun; used force to have sex. The third and fourth section asks you about how you may have acted towards your partner in certain situations. The fifth asks you to consider and comment on a series of hypothetical scenarios where aggression arises within a couple. Aggressive acts are briefly described here, for example it may say 'Carol punched him repeatedly in the face'. The sixth and final section asks you to think about how you might behave in hypothetical situations with your partner in the future.

You will receive one research credit for taking part in this study. You will receive credit upon completion of the survey.

You must complete all six sections in one sitting, as you cannot resume from where you left off at another point in time. While you are participating, your responses will be stored in a temporary holding area as you move through the sections, but they will not be permanently saved until you complete all sections and you are given a chance to review your responses. You can stop participating in this study at any time, without giving a reason, up until you submit your completed questionnaire. If you chose to withdraw from the study before 
submitting your responses your data will not be saved. You will only receive the credits if you chose to complete the study and submit your responses.

\section{Privacy and Confidentiality}

To protect your privacy, a randomly generated number that does not identify you will automatically represent all the information you provide. Your names or other identifying information will not be stored alongside your responses. This means that individual feedback on your responses will not be provided, however, if you desire you can request a summary of aggregate results, after (August ${ }^{\text {st }}$ ), by contacting me using the details stated above.

Your de-identified data will be kept indefinitely by the research lead. It will definitely be kept for at least 5 years by the lead researcher after this research is published.

\section{What happens to the information that you provide?}

The responses you provide will be collected and combined with other participants' responses. We will then analyse the data, and look at overall patterns of responses. The results will be written up in the form of scholarly articles or presentations where we will talk about the general pattern of results. The lead researcher may also use your data in other related projects, and share it with competent professionals. When any of these things occur - data is shared, results are described, articles are written, or scientific presentations are given-it will be impossible for anyone to identify you.

\section{If you have any questions or problems, whom can you contact?}

- If you have any questions about this study, either now or in the future, please feel free to contact me using the details stated at the top of this information document. 
- If you wish to discuss issues around aggression in relationships with someone, there are many avenues of free support, such as:

○ The Samaritans (0800 726 666);

○ The Family Violence Information Line (0800 456450 );

○ Lifeline Aotearoa (0800 543 354);

○ Youthline (0800 376633);

○ Victoria student counselling services (Appointments and general enquiries: Kelburn and Te Aro campus’: 04-463 5310; Pipitea campus: 04-463 7474).

\section{Thank you for considering participating in this research.}

\section{CONSENT TO PARTICIPATE}

I have read and understood the information about this research project. I understand the purpose of this research, what will happen if I participate, and what will happen to the information I provide. I understand the measures that have been put in place to protect my privacy and confidentiality. For example, I understand that a randomly generated number, that does not identify me, will represent the information I provide. I understand that I can withdraw my consent at any time prior to submitting the questionnaire online without providing a reason.

I agree to participate in this research, and I understand that checking (ticking) the box below indicates my consent.

[Box] Yes, I agree to participate in this research.

If you do not agree to participate in this research, please exit this browser window now. 


\title{
Appendix B: Debriefing statement
}

\section{EXPERIENCES AND PERCEPTIONS OF AGGRESSION IN INTIMATE \\ RELATIONSHIPS}

\section{Debriefing Statement: Project \# 2254}

\author{
Louise Dixon, Reader \\ Louise.Dixon@vuw.ac.nz

\section{Saara Cavanagh} \\ cavanasaar@myvuw.ac.uk
}

Thank you for participating in this research study.

The research literature that examines aggressive behaviour in general shows that individuals who think aggression is an acceptable behaviour are at an increased likelihood of carrying out aggressive actions. This has allowed intervention programmes aimed at changing aggressor's hostile cognition, which in turn reduces incidents of aggression, to be developed. However, despite family violence being the most common form of violent crime, this finding has rarely been explored for aggression between intimate partners, and certainly not for women who aggress against their partners. As a result, interventions do not know what belief systems to target in order to change aggressive behaviour in men and women who aggress against their intimate partner.

This study aimed to address this gap in the literature using a correlational design. It first set out to explore what student's beliefs about the acceptability of aggression to men and women 
in heterosexual relationships are. Next, it sought to explore if the resulting beliefs were associated with an increased likelihood of aggression to a partner. It is expected that the more acceptable men and women believe it is to hit people in relationships, the more likely they are to aggress against their partner.

Research with student populations in the area of partner violence is highly beneficial. There are high rates of dating violence in student and younger populations and so professionals can a learn a lot from research with you and your peers. Understanding the causes of aggressive and non-aggressive behavior can help professionals to design interventions that prevent aggression in relationships. It therefore has great practical value and your contribution is very important to preventing family violence.

If you have experienced or perpetrated relationship violence, or indeed if you find the contents of this questionnaire upsetting for some other reason and wish to discuss any issues about relationship aggression, there are many avenues of free support, such as:

The Samaritans (0800 726 666);

$>$ The Family Violence Information Line (0800 456 450);

D Lifeline Aotearoa (helpline: 0800543 354);

Youthline (0800 376633);

Victoria student counselling services (Appointments and general enquiries: Kelburn and Te Aro campus’: 04-463 5310; Pipitea campus: 04-463 7474).

If you would like to keep a copy of this debrief information for your future records please take a screen shot and save it somewhere accessible to you now, and/or print a copy of this window now. 
Should you have any further questions about the study, please feel welcome to contact us using the above contact details.

Thank you once again for your help.

Sincerely,

Dr. Louise Dixon and Saara Cavanagh 